Discussion Paper No. 1021

\title{
NAKED EXCLUSION UNDER EXCLUSIVE-OFFER COMPETITION
}

\author{
Hiroshi Kitamura \\ Noriaki Matsushima \\ Misato Sato
}

March 2018

The Institute of Social and Economic Research

Osaka University

6-1 Mihogaoka, Ibaraki, Osaka 567-0047, Japan 


\title{
Naked Exclusion under Exclusive-offer Competition*
}

\author{
Hiroshi Kitamura $^{\dagger} \quad$ Noriaki Matsushima ${ }^{\ddagger}$ Misato Sato ${ }^{\S}$
}

March 2, 2018

\begin{abstract}
This study constructs a model of anticompetitive exclusive-offer competition between two existing upstream firms. Under exclusive-offer competition, the upstream firm's profit depends on the rival's exclusive offer. If the rival makes an exclusive offer acceptable for the downstream firm, the upstream firm is excluded unless it succeeds in exclusion. Consequently, the upper bound of exclusive offers becomes higher than when one of the upstream firms is a potential entrant that cannot make any exclusive offer. Thus, the exclusion of the existing upstream firm can be an equilibrium outcome even in the case where the potential entrant is never excluded.
\end{abstract}

JEL classification codes: L12, L41, L42.

Keywords: Antitrust policy; Exclusive dealing; Exclusive-offer competition; Imperfect competition.

${ }^{*}$ We thank Takanori Adachi, Masaki Aoyagi, Jay Pil Choi, Susumu Imai, Akifumi Ishihara, Atsushi Kajii, Simon Loertscher, Toshihiro Matsumura, Stuart McDonald, Masao Ogaki, Johannes Paha, Jérôme Pouyet, Takeharu Sogo, and Zhiyong Yao as well as the conference participants at the 2nd Asia-Pacific Industrial Organisation Conference (University of Auckland), 44th European Association for Research in Industrial Economics Annual Conference (Maastricht University), 15th Annual International Industrial Organization Conference (Renaissance Boston Waterfront Hotel), and XXXII Jornadas de Economía Industrial (Universidad de Navarra) and seminar participants at Keio University, Kyoto Sangyo University, Osaka University, Sapporo Gakuin University, and Tohoku University. We gratefully acknowledge the financial support from JSPS KAKENHI grant numbers JP15H03349, JP15H05728, JP15K17060, JP17H00984, JP17J03400, and JP17K13729. The usual disclaimer applies.

${ }^{\dagger}$ Faculty of Economics, Kyoto Sangyo University, Motoyama, Kamigamo, Kita-Ku, Kyoto, Kyoto 603-8555, Japan. E-mail: hiroshikitamura@cc.kyoto-su.ac.jp

\#Institute of Social and Economic Research, Osaka University, 6-1 Mihogaoka, Ibaraki, Osaka 567-0047, Japan. E-mail: nmatsush@iser.osaka-u.ac.jp

${ }^{\S}$ Postdoctoral Research Fellow of the Japan Society for the Promotion of Science (JSPS), Faculty of Economics, Kyoto Sangyo University, Motoyama, Kamigamo, Kita-Ku, Kyoto, Kyoto 603-8555, Japan. E-mail: smisato@gwmail.gwu.edu 


\section{Introduction}

Exclusive contracts have been a controversial issue in competition policy because they are seemingly anticompetitive due to the exclusion of rival firms. However, by taking into account all members' participation constraints for such exclusive dealing in the contract party under a one-seller-one-buyer framework, Posner (1976) and Bork (1978) show that such contracts do not exist and conclude that rational economic agents do not engage in anticompetitive exclusive dealing 1 In rebuttal to the Chicago School argument, post-Chicago economists indicate specific circumstances under which anticompetitive exclusive dealing occurs (Aghion and Bolton, 1987; Rasmusen, Ramseyer, and Wiley, 1991; Segal and Whinston, 2000; Simpson and Wickelgren, 2007; Abito and Wright, 2008).

The common feature of these studies by the post-Chicago economists is that the entrant is a potential entrant, which cannot make an exclusive offer. However, in real business situations, exclusive contracts can be signed to deter existing firms. For example, in the Intel antitrust case, AMD and Transmeta, which were already in the market, were excluded.2 Furthermore, in the case of Virgin Atlantic Airways vs. British Airways, the former charged that it was excluded through British Airways' exclusive dealing with corporate customers and travel agents 3 In these cases, the excluded firms might also be able to make exclusive offers 4 More importantly, in the "cola wars" between PepsiCo and Coca-Cola, both firms ac-

\footnotetext{
${ }^{1}$ For the analysis of the impact of this argument on antitrust policies, see Motta (2004), Whinston (2006), and Fumagalli, Motta, and Calcagno (2018).

${ }^{2}$ Intel was accused of awarding rebates and making various other payments to major original equipment manufacturers (e.g., Dell and HP). See Gans (2013) for an excellent case study of the Intel case.

${ }^{3}$ Virgin Atlantic Airways charged that British Airways granted rebates to travel agents or corporate customers only if they purchase all or a certain percentage of their travel requirements from British Airways. See "Virgin Atlantic Airways v. British Airways, 872 F. Supp. 52 (S.D.N.Y. 1994)" JUSTIA US LAW, December 30, 1994 (link).

${ }^{4}$ The other example of excluding existing rivals is found in aviation industry. The Boeing Company and Airbus sometimes award exclusivity to one or two jet engine makers over the others. For example, The Boeing Company selects General Electric as the exclusive engine supplier for Boeing 777X in 1999. Airbus grants an exclusive contract to Rolls-Royce for the A330neo in 2014. See "GE Unit Lands Exclusive Boeing Pact For Developing Commercial Jet Engine" The Wall Street Journal, July 8, 1999 (link) and "Airbus selects Rolls-
} 
tually make exclusive offers and retailers, restaurants, cinemas, and universities choose one exclusive offer over the other to obtain a large monetary transfer from either supplier 5 Thus, this study aims to ascertain how exclusive-offer competition affects anticompetitive exclusive dealing.

In this study, we construct a model of anticompetitive exclusive contracts that deter an existing upstream firm. Although most previous studies assume that upstream firms produce perfectly homogeneous products, we assume that upstream firms produce horizontally differentiated products so that they earn positive profits under upstream duopoly. This modeling strategy is close to that of Wright (2008). Although Wright (2008) assumes that multiple downstream firms play an essential role in exclusion, we assume the presence of only a single downstream firm to clarify the role of exclusive-offer competition. Following previous studies, an exclusive offer involves a fixed compensation. After the downstream firm's decision on whether to accept exclusive offers, the industry profit allocation is determined by negotiations between the downstream firm and each existing upstream firm through generalized Nash bargaining. In this setting, we compare the case where one of the upstream firms is a potential entrant that cannot make exclusive offers (benchmark analysis) with the case where both upstream firms are existing firms (main analysis).

By introducing non-linear wholesale pricing and a general demand function, we first show that exclusion never occurs and that the upstream market always becomes a duopoly in the benchmark analysis; that is, the Chicago School argument can be applied. When the exclusive offer is rejected, upstream competition induces the downstream firm to earn higher profits. By considering the industry profit allocation under upstream duopoly, exclusive dealing is not profitable for the upstream incumbent because the exclusive offer acceptable for the downstream firm is costly for any bargaining power allocation.

We then show that in the main analysis, exclusion can be an equilibrium outcome. Under

Royce Trent 7000 as exclusive engine for the A330neo" Rolls-Royce, July 14, 2014 (link).

5 See, for example, “'Cola Wars' Foaming On College Campuses” Chicago Tribune, November 6, 1994 (link). The cola wars at restaurants, cinemas, and universities are discussed in Section 4.2. 
exclusive-offer competition, an upstream firm's profit depends on the rival's offer. When the rival upstream firm makes an exclusive offer acceptable for the downstream firm, the upstream firm is excluded unless it succeeds in exclusion. That is, exclusive-offer competition prevents the upstream firm from enjoying positive profits under upstream duopoly. As a result, compared with the benchmark analysis, the upstream firm has a strong incentive for exclusive dealing; the upper bound of the exclusive offer increases. Therefore, there exists a possibility that each upstream firm can profitably make a higher exclusive offer acceptable for the downstream firm. We find that this exclusion mechanism works if the downstream firm has relatively weak bargaining power because it earns lower profits for which the upstream firm can compensate easily.

We also check the robustness of the above exclusion outcome by extending the model. First, our exclusion logic can be applied in the case of linear wholesale pricing. The exclusion equilibrium exists when upstream firms are sufficiently differentiated. Second, in Appendix D, we show that the exclusion equilibrium exists for the case where downstream firms competing in quantity make exclusive supply offers to a single upstream firm. Note that in both cases, exclusion cannot be an equilibrium outcome in the absence of exclusive-offer competition. Therefore, the exclusion outcome identified in this study can be widely applied to diverse real-world vertical relationships.

This study is related to the literature on anticompetitive exclusive contracts that deter the socially efficient entry of a potential entrant. By extending the Chicago School argument's single-buyer model to a multiple-buyer model, mainstream studies introduce scale economies, wherein the entrant needs a certain number of buyers to cover its fixed costs (Rasmusen, Ramseyer, and Wiley, 1991; Segal and Whinston, 2000), and competition between buyers (Simpson and Wickelgren, 2007; Abito and Wright, 2008) 6 In these studies, negative externalities exist; signing exclusive contracts reduces the possibility of entry under

\footnotetext{
${ }^{6}$ In the literature on exclusion with downstream competition, Fumagalli and Motta (2006) show that the existence of participation fees to remain active in the downstream market plays a crucial role in exclusion if buyers are undifferentiated Bertrand competitors. See also Wright (2009), who corrects the result of Fumagalli and Motta (2006) in the case of two-part tariffs.
} 
scale economies and upstream entry reduces industry profits in the presence of downstream competition 7 By contrast, this study shows that anticompetitive exclusive contracts can be signed even under a single-buyer model because of a negative externality that the high exclusive offer by an upstream firm reduces the rival upstream firm's profits for the case of failing exclusive dealing.

In the framework of a single downstream firm, this study is related to the literature on anticompetitive exclusive contracts that deter the potential entrant focusing on the nature of upstream competition 8 The studies in this strand of the literature point out that the intensity of upstream competition plays a crucial role in the Chicago School critique. They show that the exclusion result is obtained in the cases where the incumbent sets liquidated damages for the case of entry (Aghion and Bolton, 1987), where the entrant is capacity constrained (Yong, 1996), where upstream firms compete à la Cournot (Farrell, 2005), and where upstream firms can merge (Fumagalli, Motta, and Persson, 2009).9 Our study complements these works in the sense that we show an alternative route through which the lower intensity of upstream competition due to product differentiation leads to anticompetitive exclusive dealing in the presence of exclusive-offer competition.

Few studies address exclusive dealing that aims to exclude existing firms 10 By extending the model of exclusion with downstream competition, DeGraba (2013) and Shen (2014)

\footnotetext{
${ }^{7}$ For extended models of exclusion with downstream competition, see Wright (2008), Argenton (2010), and Kitamura (2010). Whereas these studies all show that the resulting exclusive contracts are anticompetitive, Gratz and Reisinger (2013) show potentially procompetitive effects if downstream firms compete imperfectly and contract breaches are possible.

${ }^{8}$ For another mechanism of anticompetitive exclusive dealing, see Fumagalli, Motta, and Rønde (2012), who focus on the incumbent's relationship-specific investments. See also Kitamura, Matsushima, and Sato (2018), who focus on the existence of a complementary input supplier with market power.

${ }^{9}$ See also Kitamura, Matsushima, and Sato (2017a), who show that anticompetitive exclusive dealing can occur if the downstream buyer bargains with suppliers sequentially.

${ }^{10}$ Choi and Stefanadis (2017) explore the exclusive-offer competition between upstream firms before they enter the market. By extending the model of exclusion with scale economies, they point out that exclusion becomes a unique coalition-proof subgame-perfect equilibrium outcome when a derivative innovator can enter the market only if the incumbent innovator enters the market.
} 
explore exclusive-offer competition. In their studies, exclusion arises because of downstream competition. By contrast, this study explores anticompetitive exclusive dealing in the absence of downstream competition and shows that exclusive-offer competition leads to anticompetitive exclusive dealing.

In terms of exclusive-offer competition, this study is also close to the benchmark model of Bernheim and Whinston (1998, Sections II and III) 11 In their study, the exclusive offer involves wholesale prices for the case where the downstream firm rejects the exclusive offer, which is suitable for exploring short-term exclusive contracts 12 In such offers, upstream firms can commit not to sell their products to the downstream firm by setting considerably high wholesale prices for the case of rejection, which removes the downstream firm's opportunity to deal with both upstream firms. By contrast, following the standard naked exclusion literature, we assume that each upstream firm cannot commit to wholesale prices when its exclusive offer is rejected, which is suitable for long-term exclusive contracts 13 In reality, as shown by one of the cola wars' examples, PepsiCo outbid Coca-Cola for a \$14 million, 12year monopoly contract at Pennsylvania State University in 1992, which implies that it is a long-term exclusive contract. In this setting, when the downstream firm rejects both exclusive offers, it can deal with both upstream firms and earn considerably higher profits, under which the Chicago School model does not lead to anticompetitive exclusive dealing. Therefore, this study is suitable for long-term exclusive dealing and it clarifies the role of exclusive-offer competition in the literature on naked exclusion.

The remainder of this paper is organized as follows. Section 2 constructs the model. Section 3 analyzes the existence of exclusion outcomes under two-part tariffs. Section 4 provides a discussion and Section 5 offers concluding remarks. Appendix $\mathrm{A}$ provides the proofs of the results. Appendix B provides the parametric results when manufacturers operate

\footnotetext{
${ }^{11}$ See also Calzolari and Denicolò (2013, 2015), who explore upstream firms making exclusive offers in the presence of adverse selection, while we assume complete information.

12 See the discussion by Whinston (2006, p. 166).

${ }^{13}$ In addition to the commitment problem, we also consider cases in which each upstream firm does not always have full bargaining power over the downstream firm when it determines its wholesale price.
} 
at the same marginal costs under linear demand. Appendix Cintroduces the parametric results when manufacturers operate at different marginal costs under linear demand. Appendix D explores the case of exclusive supply agreements.

\section{Model}

This section develops the basic setting of the model. The upstream market consists of two manufacturers $U_{1}$ and $U_{2}$. Each manufacturer operates at the same marginal cost $c \geq 0$ and produces a final product, which is differentiated. We explore the case of the asymmetric cost function in Section 3.4. The downstream market is composed of a downstream retailer $D$, which sells the manufacturers' products. This modeling strategy clarifies the role of exclusive-offer competition because we can easily compare the result of this study with that of the Chicago School argument; exclusion never occurs in the benchmark analysis 14 To simplify the analysis, we assume that $D$ incurs no operating cost aside from paying for the product of $U_{i}$. Therefore, given wholesale price $w_{i}$, the resale cost of $D$ when it sells $q_{i}$ amount of $U_{i}$ 's final product to final consumers is given by $C_{D}\left(q_{1}, q_{2}\right)=\sum_{i} w_{i} q_{i}$.

The demand system has the following properties. Given the pair of manufacturers' product prices $\left(p_{1}, p_{2}\right)$, demand for $U_{1}$ 's product is denoted by $Q\left(p_{1}, p_{2}\right)$. By assuming symmetric demand, demand for $U_{2}$ 's product is denoted by $Q\left(p_{2}, p_{1}\right)$. When the prices of these manufacturers' products are sufficiently close, both obtain positive demand. However, when these prices differ sufficiently, the higher priced manufacturer loses demand, while the lower priced manufacturer obtains all demand. The degree of product substitution between manufacturers' products is represented by $\gamma \in(0,1)$. Manufacturers' products become homogeneous as the value of $\gamma$ increases. For $\gamma=0$, manufacturers produce independent goods. Alternatively, for $\gamma=1$, manufacturers produce perfectly substitutes. In addition, when $U_{j}$ is excluded, demand for $U_{i}$ 's product does not depend on $\gamma$, where $i, j \in\{1,2\}$ and $i \neq j$. We denote demand for $U_{i}$ 's product in the monopoly case by $Q\left(p_{i}\right) \equiv Q\left(p_{i}, \infty\right)$.

\footnotetext{
${ }^{14}$ Although a buyer is the final consumer in the Chicago School model, the results in all the propositions in this paper do not change if we assume that the buyer is a downstream monopolist.
} 
For the sake of the analysis under generalized Nash bargaining, we assume that industry profits under exclusive dealing $\left(p_{i}-c\right) Q\left(p_{i}\right)$ and those under non-exclusion cases $\left(p_{i}-c\right) Q\left(p_{i}, p_{j}\right)+\left(p_{j}-c\right) Q\left(p_{j}, p_{i}\right)$ are globally and strictly concave and satisfy the secondorder conditions. We define $p_{m}$ and $p_{d}$ as follows:

$$
\begin{gathered}
p_{m} \equiv \underset{p_{i}}{\arg \max }\left(p_{i}-c\right) Q\left(p_{i}\right), \\
\left(p_{d}, p_{d}\right) \equiv \arg \max _{p_{i}, p_{j}}\left(p_{i}-c\right) Q\left(p_{i}, p_{j}\right)+\left(p_{j}-c\right) Q\left(p_{j}, p_{i}\right) .
\end{gathered}
$$

We define $\Pi_{m}$ and $\Pi_{d}$ as the net profit of each vertical chain under upstream monopoly and under upstream duopoly:

$$
\Pi_{m} \equiv\left(p_{m}-c\right) Q\left(p_{m}\right), \quad \Pi_{d} \equiv\left(p_{d}-c\right) Q\left(p_{d}, p_{d}\right)
$$

We assume the following relationship:

Assumption 1. For all $0<\gamma<1$,

$$
2 \Pi_{d}>\Pi_{m}>\Pi_{d}
$$

where $\partial \Pi_{m} / \partial \gamma=0, \partial \Pi_{d} / \partial \gamma<0, \Pi_{d} \rightarrow \Pi_{m}$ as $\gamma \rightarrow 0$, and $2 \Pi_{d} \rightarrow \Pi_{m}$ as $\gamma \rightarrow 1$.

The first inequality of Condition (1) is the key property in this study, which implies that an increase in the number of product varieties generates an additional industry value except when $\gamma=1$. In addition, the second inequality in Condition (1) implies that an increase in the number of product varieties reduces the net profit per vertical chain except when $\gamma=0$. Note that the properties introduced above hold under standard linear demand with a representative consumer, which is introduced when we explore the case of linear wholesale pricing in Section 4

The model contains three stages. In Stage $1, U_{1}$ and $U_{2}$ make an exclusive offer to $D$ with fixed compensation $x_{i} \geq 0$. Following the standard literature on naked exclusion, we 
assume that each exclusive offer does not contain the term of wholesale prices $15 D$ can reject both offers or it can accept one of the offers. Let $\omega \in\{R, E 1, E 2\}$ be $D$ 's decision in Stage 1. $D$ immediately receives $x_{i}$ if it accepts $U_{i}$ 's exclusive offer. If $D$ is indifferent between two exclusive offers and acceptance leads to higher profits, it accepts one of the offers with probability 1/2. In Stage 2, active manufacturers offer a two-part tariff contract. We extend the model to the case of linear wholesale pricing in Section 4. In Stage 3,D orders the final product and sells it to consumers at $p_{i}^{\omega}$. $U_{i}$ 's profit is denoted by $\pi_{U i}^{\omega}$. Likewise, $D$ 's profit is denoted by $\pi_{D}^{\omega}$.

\section{Two-part tariffs}

This section analyzes the existence of anticompetitive exclusive contracts under two-part tariffs, which consist of a linear wholesale price and an upfront fixed fee; the two-part tariff offered by $U_{i}$ when $D$ 's decision is $\omega \in\{R, E 1, E 2\}$ is denoted by $\left(w_{i}^{\omega}, F_{i}^{\omega}\right)$, where $i \in\{1,2\}$. We assume that the industry profit allocation after Stage 1 is given by the Nash bargaining solution and that the net joint surplus is divided between $D$ and each manufacturer in the proportion $\beta$ to $1-\beta$, where $\beta \in(0,1)$ represents $D$ 's bargaining power.

The rest of this section is organized as follows. Section 3.1 derives the equilibrium outcomes after the game in Stage 1 by using backward induction. Section 3.2 examines the game in Stage 1 by introducing the benchmark analysis in which one of the manufacturers is a potential entrant as in the Chicago School model. Section 3.3 then explores the case where both manufacturers make exclusive offers. Section 3.4 finally examines the effect of cost asymmetry on the existence of an exclusion equilibrium.

\footnotetext{
${ }^{15}$ Rasmusen, Ramseyer, and Wiley (1991) and Segal and Whinston (2000) point out that price commitments are unlikely if the product's nature is not precisely described in advance. In the naked exclusion literature, it is known that if the incumbent can commit to wholesale prices, then the possibility of anticompetitive exclusive dealing is enhanced. See Yong (1999) and Appendix B of Fumagalli and Motta (2006).
} 


\subsection{Equilibrium outcomes after Stage 1}

We first consider the case in which $U_{i}$ 's exclusive offer is accepted in Stage 1. Note that for notational simplicity, we do not discuss explicitly how the wholesale price is determined in each instance of bargaining because we can easily show that marginal cost pricing is achieved in all cases by using the envelope theorem. In Stage 2, $D$ negotiates with $U_{i}$ and makes a twopart tariff contract, $\left(c, F_{i}^{E i}\right)$. The bargaining problem between $D$ and $U_{i}$ is described by the payoff pairs $\left(\Pi_{m}-F_{i}^{E i}, F_{i}^{E i}\right)$ and the disagreement point $(0,0)$. The solution is given by

$$
F_{i}^{E i}=\arg \max _{F_{i}} \beta \log \left[\Pi_{m}-F_{i}\right]+(1-\beta) \log F_{i} .
$$

The maximization problem leads to

$$
F_{i}^{E i}=(1-\beta) \Pi_{m}
$$

The firms' equilibrium profits, excluding the fixed compensation $x_{i}$, are

$$
\pi_{U i}^{E i}=(1-\beta) \Pi_{m}, \quad \pi_{U j}^{E i}=0, \quad \pi_{D}^{E i}=\beta \Pi_{m} .
$$

Depending on the bargaining power $\beta, U_{i}$ and $D$ split the monopoly profit, $\Pi_{m}$.

We next consider the case in which $D$ rejects both exclusive offers in Stage 1. In this case, $D$ sells both manufacturers' products. We assume that the bargaining in Stage 2 takes the form of simultaneous bilateral negotiation; that is, when negotiating with two manufacturers, $D$ simultaneously and separately negotiates with each of them. $D$ and $U_{i}$ then make a twopart tariff contract, $\left(c, F_{i}^{R}\right)$. The outcome of each negotiation is given by the Nash bargaining solution based on the belief that the outcome of the bargaining with the other party is determined in the same way. The bargaining problem between $D$ and $U_{i}$ is described by the payoff pairs $\left(2 \Pi_{d}-F_{j}^{R}-F_{i}^{R}, F_{i}^{R}\right)$ and the disagreement point $\left(z_{j}, 0\right)$, where $z_{j} \equiv \Pi_{m}-F_{j}^{R}$ is $D^{\prime}$ 's profit when it sells only $U_{j}$ 's product under two-part tariff contract $\left(c, F_{j}^{R}\right)$. The solution is given by

$$
F_{i}^{R}=\arg \max _{F_{i}} \beta \log \left[2 \Pi_{d}-F_{j}-F_{i}-z_{j}\right]+(1-\beta) \log F_{i} .
$$

The maximization problem leads to

$$
F_{i}^{R}=(1-\beta)\left(2 \Pi_{d}-\Pi_{m}\right)
$$


for each $i \in\{1,2\}$. The resulting profits of the firms are given as

$$
\pi_{U i}^{R}=(1-\beta)\left(2 \Pi_{d}-\Pi_{m}\right), \quad \pi_{D}^{R}=2\left((1-\beta)\left(\Pi_{m}-\Pi_{d}\right)+\beta \Pi_{d}\right) .
$$

$U_{i}$ obtains its additional contribution weighted by its bargaining power $1-\beta$, and $D$ earns the remaining industry profit under upstream duopoly after subtracting the payments for $U_{1}$ and $U_{2}$ (that is, $2 \Pi_{d}-\pi_{U 1}^{R}-\pi_{U 2}^{R}$ ).

\subsection{Benchmark analysis}

Assume that $U_{j}$ is a potential entrant and only $U_{i}$ can make an exclusive offer as in the Chicago School model. In this subsection, we modify the timing of Stage 1 as follows. In Stage 1.1, $U_{i}$ makes an exclusive offer $x_{i}$ and $D$ decides whether to accept the offer. After observing $D$ 's decision, $U_{j}$ decides whether to enter the upstream market in Stage 1.2. The fixed cost of entry is sufficiently small so that $U_{j}$ earns positive profits.

To start the analysis, we derive the essential conditions for an exclusive contract when only one manufacturer makes exclusive offers. For an exclusion equilibrium to exist, the equilibrium transfer $x_{i}^{*}$ must satisfy the following two conditions.

First, the exclusive contract must satisfy individual rationality for $D$; that is, the amount of compensation $x_{i}^{*}$ induces $D$ to accept the exclusive offer:

$$
\pi_{D}^{E i}+x_{i}^{*} \geq \pi_{D}^{R} \text { or } x_{i}^{*} \geq \Delta \pi_{D} \equiv \pi_{D}^{R}-\pi_{D}^{E i}
$$

where $\Delta \pi_{D}$ is the absolute value of $D$ 's profit loss under exclusive dealing.

Second, it must satisfy individual rationality for $U_{i}$; that is, $U_{i}$ earns higher profits under exclusive dealing:

$$
\pi_{U i}^{E i}-x_{i}^{*} \geq \pi_{U i}^{R} \text { or } x_{i}^{*} \leq \Delta \pi_{U} \equiv \pi_{U i}^{E i}-\pi_{U i}^{R},
$$

where $\Delta \pi_{U}$ is $U_{i}$ 's profit increase under exclusive dealing. Note that $\Delta \pi_{U}=\pi_{U 1}^{E 1}-\pi_{U 1}^{R}=$ $\pi_{U 2}^{E 2}-\pi_{U 2}^{R}$

From the above conditions, it is evident that an exclusion equilibrium exists if and only if inequalities (4) and (5) simultaneously hold. This is equivalent to the following condition:

$$
\Delta \pi_{U} \geq \Delta \pi_{D} \text { or } \pi_{U i}^{E i}+\pi_{D}^{E i} \geq \pi_{U i}^{R}+\pi_{D}^{R}
$$


Condition (6) implies that anticompetitive exclusive contracts are attained if exclusive contracts increase the joint profits of $U_{i}$ and $D$ or equivalently if $U_{i}$ 's profit increase is higher than $D$ 's profit loss under exclusive dealing.

By using the subgame outcomes derived in the previous subsection, we now consider the game in Stage 1. By substituting Equations (2) and (3), we find that under Condition (1)

$$
\Delta \pi_{U}-\Delta \pi_{D}=-\beta\left(2 \Pi_{d}-\Pi_{m}\right)<0,
$$

which implies that exclusion never occurs.

Proposition 1. Suppose both manufacturers adopt two-part tariffs. If $U_{j}$ is a potential entrant and only $U_{i}$ can make an exclusive offer, $U_{i}$ cannot exclude $U_{j}$ through exclusive contracts.

Proposition 1 confirms the robustness of the Chicago School argument when we extend its model to the case where manufacturers produce differentiated products and adopt two-part tariffs. Under the non-linear pricing scheme, following the bargaining procedure, the firms split the total industry profit. Except for the cases of $\beta=0$ and $\gamma=1$, entry by $U_{j}$ generates some additional profits for $D$, those of which are sufficient to eliminate the incentives of $D$ and $U_{i}$ to reach exclusion 16 Therefore, exclusion does not occur when only one manufacturer can make the exclusive offer.

\subsection{When exclusive-offer competition exists}

In contrast to the previous subsection, we now assume that both manufacturers are existing firms and can make exclusive offers. Compared with the case where exclusive-offer competition does not exist, the difference arises in the upper bound of $U_{i}$ 's exclusive offer $x_{i}^{\max }$, which depends on $U_{j}$ 's offer, where

$$
x_{i}^{\max } \equiv \begin{cases}\pi_{U i}^{E i} & \text { if } x_{j} \geq \Delta \pi_{D} \\ \Delta \pi_{U} & \text { if } x_{j}<\Delta \pi_{D}\end{cases}
$$

\footnotetext{
${ }^{16}$ When $\beta=0, U_{j}$ obtains all its additional contribution, implying that entry leaves nothing to $D$. When $\gamma=1, U_{j}$ does not add any contribution to the industry because of the perfect substitutability of products.
} 
Note that $\pi_{U i}^{E i}>\Delta \pi_{U}$ and that $x_{i}^{\max }=\Delta \pi_{U}$ in the benchmark case. The feature of $x_{i}^{\max }$ is explained by $D$ 's decision on whether to accept the exclusive offer by $U_{j}$. Figure 1 summarizes $D$ 's decision in response to both manufacturers' offers in Stage 1. When both exclusive offers are lower than $\Delta \pi_{D}, D$ rejects both. By contrast, when at least one of the exclusive offers is higher than or equal to $\Delta \pi_{D}, D$ accepts the better offer; more concretely, at least one of $x_{i}$ and $x_{j}$ satisfies Condition (4) in the shadowed area of Figure 1. Hence, D's behaviors affect both manufacturers' exclusive offers as follows. When $U_{j}$ offers $x_{j}<\Delta \pi_{D}, U_{i}$ can be active and earn $\pi_{U i}^{R}(>0)$ even when it fails to exclude $U_{j}$. By comparing this profit with its net profit under exclusion $\pi_{U i}^{E i}-x_{i}, U_{i}$ does not offer $x_{i}\left(>\Delta \pi_{U}\right)$ as in the benchmark case. On the contrary, when $U_{j}$ 's exclusive offer satisfies $x_{j} \geq \Delta \pi_{D}, U_{i}$ is out of the market and earns $\pi_{U i}^{E j}=0$ if it fails to exclude $U_{j}$. In this case, the exclusion of $U_{j}$ is profitable for $U_{i}$ if $\pi_{U_{i}}^{E i}-x_{i} \geq 0$. Therefore, $U_{i}$ makes a higher exclusive offer if $x_{j} \geq \Delta \pi_{D}$.

[Figure 1] about here]

Figures 2 and 3 summarize the set of each manufacturer's feasible offer $\left(x_{1}, x_{2}\right)$ that satisfies $x_{i} \in\left[0, x^{\max }\right]$ for each $i \in\{1,2\}$. Each manufacturer's offer is feasible in the shadowed area of Figures 2 and 3, which can be a candidate for the set of exclusion offers in the exclusion equilibrium $\left(x_{1}^{* *}, x_{2}^{* *}\right)$; in other words, other areas cannot be the exclusion equilibrium.

Depending on the magnitude relationship between $\pi_{U i}^{E i}$ and $\Delta \pi_{D}$, we have two cases. First, if $\pi_{U i}^{E i}<\Delta \pi_{D}$, summarized in Figure 2, each manufacturer's exclusive offer is feasible in only one region because $D$ 's rejection profit is considerably high and each manufacturer cannot compensate $D$ profitably when its rival makes the higher offer. Second, if $\pi_{U i}^{E i} \geq \Delta \pi_{D}$, summarized in Figure 3, each manufacturer's exclusive offer is feasible in two regions. Because $D$ 's rejection profit is not too high in this case, $U_{i}$ can profitably offer $x_{i}\left(\geq \Delta \pi_{D}\right)$ when $U_{j}$ makes the high offer $x_{j} \geq\left(\Delta \pi_{D}\right)$.

[Figures 2 and 3 about here]

To explore the existence of an exclusion equilibrium, we now combine the results in Figures 1, 2, and 3, Figures 4 and 5 combine these figures and $D$ 's decision in the shadowed 
areas in Figures 2 and 3. Figure 4 implies that exclusion never occurs if $\pi_{U i}^{E i}<\Delta \pi_{D}$. In this case, there exist only non-exclusion equilibria in which each manufacturer offers $x_{i} \in\left[0, \Delta \pi_{D}\right)$ and $D$ rejects both offers. By contrast, Figure 5 shows that an exclusion equilibrium exists if $\pi_{U i}^{E i} \geq \Delta \pi_{D}$. The candidate for the equilibrium offer is the area in which $\left(x_{1}, x_{2}\right) \in\left[\Delta \pi_{D}, \pi_{U_{i}}^{E i}\right]^{2}$ holds. Obviously, $x_{i}>x_{j} \geq \Delta \pi_{D}$ and $x_{i}=x_{j}<\pi_{U_{i}}^{E i}$ cannot be an equilibrium because at least one of the manufacturers has an incentive to deviate. There exists the exclusion equilibrium in which each manufacturer offers $x_{i}^{* *}=\pi_{U i}^{E i}$ and $D$ accepts one of the offers. Note that even when $\pi_{U i}^{E i} \geq \Delta \pi_{D}$, there also exists the non-exclusion equilibria in which each manufacturer offers $x_{i} \in\left[0, \Delta \pi_{D}\right)$ and $D$ rejects both offers.

[Figures 4 and 5 about here]

We finally consider the existence of an exclusion equilibrium. From the above discussion, we need to check whether $\pi_{U i}^{E i} \geq \Delta \pi_{D}$ holds. By substituting Equations (2) and (3), we obtain

$$
\pi_{U i}^{E i}-\Delta \pi_{D}=(1-2 \beta)\left(2 \Pi_{d}-\Pi_{m}\right) \geq 0
$$

if and only if $\beta \in(0,1 / 2]$, which implies that an exclusion equilibrium exists for the weak bargaining power of $D$.

Proposition 2. Suppose that both manufacturers make exclusive offers in Stage 1 and adopt two-part tariffs in Stage 2. If D has strong bargaining power $(\beta>1 / 2)$, exclusion cannot be an equilibrium outcome. By contrast, if $D$ has weak bargaining power $(\beta \leq 1 / 2)$, there exist both an exclusion equilibrium and non-exclusion equilibria.

Proposition 2 shows that under exclusive-offer competition, an exclusion equilibrium exists depending on the bargaining power of $D$ over manufacturers. For the weak bargaining power of $D, D$ earns a lower profit when it rejects both exclusive offers in Stage 1. Therefore, each manufacturer can compensate $D$ profitably. Moreover, the existence of an exclusion equilibrium does not depend on the degree of product substitution $\gamma$ under non-linear wholesale pricing. Note that the result here highly depends on the assumption that manufacturers' 
costs are symmetric. In the following subsection, we explore the case of an asymmetric cost structure and show that the exclusion equilibrium is more likely to be observed for lower $\gamma$.

Note that Proposition 2 shows that exclusion is not a unique equilibrium outcome. By comparing the two types of equilibria, the manufacturers strictly prefer the non-exclusion equilibria to the exclusion equilibrium. Seemingly, the cola wars capture the exclusion equilibrium because both Coca-Cola and PepsiCo pay a large monetary transfer. The likelihood of exclusion here may depend on the market history. If a president of one upstream firm has a managerial incentive to maximize market share rather than profit, exclusion is more likely to occur. Once exclusion occurs, it is more likely to be observed continuously-even when the managerial incentive changes. In addition, $D$ has a strong incentive to yield the exclusion outcome. Because Condition (4) holds with strict inequality under the exclusion equilibrium, $D$ prefers the exclusion equilibrium to the non-exclusion equilibrium. Hence, $D$ may try to do something to yield the exclusion outcome.

\subsection{Cost asymmetry}

This subsection briefly discusses the effect of cost asymmetry on the existence of an exclusion equilibrium. Thus far, we have assumed that each manufacturer operates at the same marginal cost $c \geq 0$. We now extend the model to the case in which manufacturers operate at different marginal costs. Without loss of generality, we assume that the marginal cost of $U_{1}$ is lower than that of $U_{2}$, namely $0 \leq c_{1}<c_{2}$. We define $p_{m i}$ and $p_{d i}$ as follows:

$$
\begin{aligned}
& p_{m i} \equiv \arg \max _{p_{i}}\left(p_{i}-c_{i}\right) Q\left(p_{i}\right), \\
& \left(p_{d i}, p_{d j}\right) \equiv \arg \max _{p_{i}, p_{j}}\left(p_{i}-c_{i}\right) Q\left(p_{i}, p_{j}\right)+\left(p_{j}-c_{j}\right) Q\left(p_{j}, p_{i}\right) .
\end{aligned}
$$

We define $\Pi_{m i}$ and $\Pi_{d i}$ as the net profit of $U_{i}$ 's vertical chain under upstream monopoly and upstream duopoly:

$$
\Pi_{m i} \equiv\left(p_{m i}-c_{i}\right) Q\left(p_{m i}\right), \quad \Pi_{d i} \equiv\left(p_{d i}-c_{i}\right) Q\left(p_{d i}, p_{d j}\right)
$$


Since our focus is the existence of anticompetitive exclusive dealing, we only consider the case where the upstream market becomes a duopoly in the absence of exclusive dealing, namely $\Pi_{d i}>0$ for each $i \in\{1,2\}$. For the sake of notational convenience, we define

$$
\Delta \Pi_{i} \equiv \Pi_{d i}+\Pi_{d j}-\Pi_{m j}
$$

which can be interpreted as the level of increment in the industry profit when $U_{i}$ 's product is also launched in the upstream market monopolized by $U_{j}$. As in Assumption 1, we assume the following relationships:

Assumption 2. $\Pi_{m i}$ and $\Pi_{d i}$ have the following properties:

1. Trading with $U_{1}$ leads to higher profits than that with $U_{2}$;

$$
\Pi_{m 1}>\Pi_{m 2}, \quad \Pi_{d 1}>\Pi_{d 2} .
$$

2. For each $i \in\{1,2\}$ and $\gamma \in(0,1)$,

$$
\Pi_{d 1}+\Pi_{d 2}>\Pi_{m i}>\Pi_{d i}
$$

where $\partial \Pi_{m i} / \partial \gamma=0, \partial \Pi_{d i} / \partial \gamma<0, \Pi_{d i} \rightarrow \Pi_{m i}$ as $\gamma \rightarrow 0$, and $\Pi_{d 2} \rightarrow 0$ and $\Pi_{d 1} \rightarrow \Pi_{m 1}$ for sufficiently high $\gamma$.

3. $\Delta \Pi_{1}$ is decreasing in $c_{1}$ but $\Delta \Pi_{2}$ is increasing in $c_{1}$ :

$$
\frac{\partial \Delta \Pi_{1}}{\partial c_{1}}<0, \frac{\partial \Delta \Pi_{2}}{\partial c_{1}}>0
$$

Note that Conditions (8) and (9) imply that

$$
\Delta \Pi_{1}>\Delta \Pi_{2}>0
$$

By using the above definitions, we can derive the equilibrium profits under asymmetric costs. As in Section 3.1, the negotiation between $D_{i}$ and $U_{i}$ leads to marginal cost pricing in 
all cases. Under generalized Nash bargaining, the firms' equilibrium profits under exclusive dealing, excluding the fixed compensation $x_{i}$, are

$$
\pi_{U i}^{E i}=(1-\beta) \Pi_{m i}, \quad \pi_{U j}^{E i}=0, \quad \pi_{D}^{E i}=\beta \Pi_{m i}
$$

By contrast, the firms' equilibrium profits under non-exclusive dealing are

$$
\pi_{U i}^{R}=(1-\beta) \Delta \Pi_{i}, \quad \pi_{D}^{R}=(1-\beta)\left(\Pi_{m i}-\Pi_{d i}+\Pi_{m j}-\Pi_{d j}\right)+\beta\left(\Pi_{d i}+\Pi_{d j}\right)
$$

From Condition (10), we have $\partial \pi_{U 1}^{R} / \partial c_{1}<0$ but $\partial \pi_{U 2}^{R} / \partial c_{1}>0$, which is observed in the linear demand model 17

We now consider the existence of an exclusion equilibrium. We first explore the case in which only $U_{i}$ can make an exclusive offer. By substituting Equations (12) and (13), we find that under Condition (9)

$$
\pi_{U i}^{E i}+\pi_{D}^{E i}-\left(\pi_{U i}^{R}+\pi_{D}^{R}\right)=-\beta \Delta \Pi_{j}<0
$$

which implies that exclusion never occurs.

Proposition 3. Suppose both manufacturers adopt two-part tariffs. If $U_{j}$ is a potential entrant and only $U_{i}$ can make an exclusive offer, $U_{i}$ cannot exclude $U_{j}$ through exclusive contracts even under asymmetric costs.

Proposition 3 implies that $U_{1}$ cannot deter the entry of $U_{2}$ as long as entry increases the industry profit. Therefore, the result confirms the robustness of the Chicago School argument in the case where the incumbent manufacturer cannot deter the entry of a potential entrant manufacturer, which is even less efficient.

We next consider the case in which both manufacturers make exclusive offers. Note that the exclusion equilibrium exists if and only if $\pi_{U i}^{E i}+\pi_{D}^{E i} \geq \pi_{D}^{R}$ holds for each $i \in\{1,2\}$. By substituting Equations (12) and (13), we have $\pi_{U i}^{E i}+\pi_{D}^{E i}-\pi_{D}^{R} \geq 0$ if and only if

$$
\beta \leq \beta_{i} \equiv \frac{\Delta \Pi_{i}}{\Delta \prod_{i}+\Delta \Pi_{j}}
$$

\footnotetext{
${ }^{17}$ See Appendix C, which introduces the results under the linear demand model.
} 
for each $i \in\{1,2\}$. From Conditions (11) and (14), $\beta_{i}$ have the following relationships:

$$
0<\beta_{2}<\frac{1}{2}<\beta_{1}<1,
$$

where $\beta_{1} \rightarrow 1$ and $\beta_{2} \rightarrow 0$ as $\Delta \Pi_{2} \rightarrow 0$. Condition (15) shows that $\beta_{1}>\beta_{2}$ always holds; thus, the exclusion equilibrium exists if and only if $\beta \leq \beta_{2}$. Because $\beta_{2}<1 / 2$ always holds, cost asymmetry reduces the possibility of the exclusion equilibrium. More precisely, by differentiating $\beta_{i}$ with respect to $c_{1}$, we have

$$
\frac{\partial \beta_{i}}{\partial c_{1}}=\frac{1}{\left(\Delta \Pi_{i}+\Delta \Pi_{j}\right)^{2}}\left(\frac{\partial \Delta \Pi_{i}}{\partial c_{1}} \Delta \Pi_{j}-\frac{\partial \Delta \Pi_{j}}{\partial c_{1}} \Delta \Pi_{i}\right) .
$$

Under Condition (10), we have $\partial \beta_{1} / \partial c_{1}<0$ and $\partial \beta_{2} / \partial c_{1}>0$. Therefore, as $U_{1}$ becomes more efficient, $\beta_{2}$ decreases; in other words, the exclusion equilibrium is less likely to exist. The following proposition summarizes the results provided above.

Proposition 4. Suppose that both manufacturers make exclusive offers in Stage 1 and adopt two-part tariffs in Stage 2. As the degree of cost asymmetry increases, exclusion is less likely to be an equilibrium outcome.

The result in Proposition 4 implies that the exclusion mechanism in this study is more likely to work well when each manufacturer has a similar cost structure. When $U_{1}$ 's efficiency increases, the industry profit under duopoly $\Pi_{d 1}+\Pi_{d 2}$ increases, which allows $D$ to earn higher profits under upstream duopoly because $\partial \pi_{D}^{R} / \partial c_{1}=-(1-\beta) \partial \Delta \Pi_{2} / \partial c_{1}+\beta\left(\partial \Pi_{d 1} / \partial c_{1}+\right.$ $\left.\partial \Pi_{d 2} / \partial c_{2}\right)<0$. By contrast, the increase in $U_{1}$ 's efficiency does not affect $U_{2}$ 's monopoly profit under exclusive dealing; hence, $U_{2}$ has difficulty in compensating $D$. Therefore, the possibility of exclusion becomes lower under cost asymmetry.

Finally, we explore the relationship between the existence of an exclusion equilibrium and the degree of product substitution $\gamma$. By differentiating $\beta_{i}$ with respect to $\gamma$, we have

$$
\frac{\partial \beta_{i}}{\partial \gamma}=\frac{\Pi_{m j}-\Pi_{m i}}{\left(\Delta \Pi_{i}+\Delta \Pi_{j}\right)^{2}}\left(\frac{\partial \Pi_{d i}}{\partial \gamma}+\frac{\partial \Pi_{d j}}{\partial \gamma}\right)>0 \text { if and only if } \Pi_{m i}>\Pi_{m j} .
$$

From Condition (8), we have $\partial \beta_{1} / \partial \gamma>0$ and $\partial \beta_{2} / \partial \gamma<0$, which lead to the following proposition. 
Proposition 5. Suppose that both manufacturers make exclusive offers in Stage 1 and adopt two-part tariffs in Stage 2. Under cost asymmetry, the exclusion equilibrium is more likely to be observed for the cases in which the manufacturers produce highly differentiated products.

The result in Proposition 5 implies that under cost asymmetry, the existence of an exclusion equilibrium is determined by the degree of product substitution $\gamma$; in other words, the result in Proposition 2 highly depends on the symmetric cost structure. The result here is explained by the property of bargaining when $D$ rejects both exclusive offers. By differentiating $\pi_{D}^{R}$ with respect to $\gamma$, we have

$$
\frac{\partial \pi_{D}^{R}}{\partial \gamma}=(2 \beta-1)\left(\frac{\partial \Pi_{d 1}}{\partial \gamma}+\frac{\partial \Pi_{d 2}}{\partial \gamma}\right)>0 \text { for } \beta<1 / 2,
$$

which implies that as the manufacturers produce less differentiated products, $D$ earns high profits under upstream duopoly for the weak bargaining power of $D$. The degree of product substitution affects $D$ 's profit under upstream duopoly in two ways. First, as $\gamma$ increases, the industry profit $\Pi_{d i}+\Pi_{d j}$ directly decreases, which has the negative effect of decreasing $\pi_{D}^{R}$. Second, because $U_{i}$ 's additional contribution decreases, it earns lower profits $\pi_{U i}^{R}=F_{i}^{R}$, which indirectly increases $D$ 's outside option profit under the bargaining with $U_{j}, z_{j}=\Pi_{m i}-F_{i}^{R}$. This indirect effect increases $\pi_{D}^{R}$ and becomes dominant for lower $\beta$ because the strong bargaining power of $U_{i}$ decreases $F_{i}^{R}$ largely. Under this relationship, as the manufacturers produce more differentiated products when the downstream firm has weak bargaining power, $U_{2}$ can compensate $D$ more easily; thus, the exclusion equilibrium is more likely to be observed 18

\section{Discussion}

This section briefly discusses the wholesale pricing and real-world examples of exclusiveoffer competition. Section 4.1 extends the analysis to the case of linear wholesale pricing.

\footnotetext{
${ }^{18}$ When the downstream firm and each manufacturer have the same bargaining power $(\beta=1 / 2)$, we have $\partial \pi_{D}^{R} / \partial \gamma=0$; thus, the degree of product substitution does not affect $D$ 's profit under upstream duopoly. Since the threshold value of $D$ 's bargaining power under symmetric costs is $1 / 2$, the likelihood of exclusion under symmetric costs does not depend on product substitution.
} 
Section 4.2 introduces some examples of exclusive-offer competition.

\subsection{Linear wholesale pricing}

This subsection explores the existence of anticompetitive exclusive dealing under linear wholesale pricing by assuming standard linear demand with a representative consumer, in which demand for $U_{i}$ 's product is provided by

$$
Q\left(p_{i}, p_{j}\right)= \begin{cases}\frac{a-p_{i}}{b} & \text { if } 0<p_{i} \leq \frac{-a(1-\gamma)+p_{j}}{\gamma}, \\ \frac{a(1-\gamma)-p_{i}+\gamma p_{j}}{b\left(1-\gamma^{2}\right)} & \text { if } \frac{-a(1-\gamma)+p_{j}}{\gamma}<p_{i}<a(1-\gamma)+\gamma p_{j}, \\ 0 & \text { if } p_{i} \geq a(1-\gamma)+\gamma p_{j},\end{cases}
$$

where $i, j \in\{1,2\}$ and $i \neq j$. As in the previous section, we assume that the industry profit allocation after Stage 1 is given by the Nash bargaining solution.

We first explore the existence of an exclusion equilibrium when only $U_{i}$ can make an exclusive offer. Like the case of two-part tariffs, exclusion never occurs.

Proposition 6. Suppose both manufacturers offer linear wholesale prices. If $U_{j}$ is a potential entrant and only $U_{i}$ can make an exclusive offer, $U_{i}$ cannot exclude $U_{j}$ through exclusive contracts for any pair of bargaining power allocation and the degree of product substitution.

Proof. See Appendix A.1.

Proposition 6 implies that in the absence of exclusive-offer competition, anticompetitive exclusive dealing cannot occur, which can be explained by the logic underlying the Chicago School argument.

We next investigate the existence of an exclusion equilibrium when both manufacturers can make exclusive offers. In this case, an exclusion equilibrium exists under some conditions.

Proposition 7. Suppose that both manufacturers make exclusive offers in Stage 1 and linear wholesale prices are determined through Nash bargaining in Stage 2. When the products 
are less differentiated ( $\gamma>\tilde{\gamma} \simeq 0.77393$ ), exclusion cannot be an equilibrium outcome. By contrast, when those are sufficiently differentiated $(\gamma \leq \tilde{\gamma})$, there exist both an exclusion equilibrium and non-exclusion equilibria for a sufficiently weak bargaining power of $D$ ( $\beta \leq$ $\hat{\beta}(\gamma))$, where

$$
\hat{\beta}(\gamma) \equiv \frac{4 \phi^{2}+2 \gamma(1+\gamma)(5 \gamma-4) \phi+4 \gamma^{2}(1+\gamma)\left(\gamma^{3}+3 \gamma^{2}+3 \gamma-5\right)}{6 \gamma^{2}(1+\gamma) \phi}
$$

and

$$
\begin{aligned}
\phi & \equiv\left[\gamma^{3}(1+\gamma)^{2}\left(\gamma^{4}+4 \gamma^{3}+6 \gamma^{2}-32 \gamma+19\right)\right. \\
& \left.+3 \sqrt{6 \gamma^{6}(1+\gamma)^{2}\left(1-\gamma^{2}\right)\left(\gamma^{5}+5 \gamma^{4}+10 \gamma^{3}+5 \gamma^{3}-12 \gamma^{2}-11 \gamma+9\right)}\right]^{\frac{1}{3}} .
\end{aligned}
$$

Proof. See Appendix A.2

Note that $\hat{\beta}(\gamma)$ has a single peaked property with $\hat{\beta}(\gamma) \rightarrow 1 / 3$ as $\gamma \rightarrow 0, \hat{\beta}(\gamma) \rightarrow 0$ as $\gamma \rightarrow \tilde{\gamma}$, and the maximized value $\hat{\beta}\left(\gamma^{*}\right) \simeq 0.413049$ at $\gamma^{*} \simeq 0.469146$.

[Figure 6] about here]

Figure 6 summarizes Proposition 7 . The notable result in Proposition 7 is that linear wholesale pricing leads to the low possibility of the anticompetitive exclusion equilibrium; exclusion never occurs for the intermediate level of $D$ 's bargaining power or for less differentiated manufacturers' products.

The major difference between two types of pricing is the existence of double marginalization problems, which arise not only under exclusive dealing but also under upstream duopoly. These two double marginalization problems reduce the possibility of exclusive outcomes in the following ways. Under exclusive dealing, the contracting party cannot achieve the joint profit maximization due to the double marginalization problem. Because upstream duopoly can mitigate such a problem, manufacturers have difficulty in compensating $D$ for the intermediate level of $D$ 's bargaining power. Moreover, the mitigation effect of upstream duopoly 
depends on the degree of product substitution $\gamma$. When the manufacturers produce almost homogeneous products, the double marginalization problem under upstream duopoly is not too serious, which allows $D$ to earn large rejection profits $\pi_{D}^{R}$. Hence, the exclusion equilibrium does not exist when the products are less differentiated.

\subsection{Cola wars in the real world}

In this subsection, we provide examples of exclusive-offer competition in the soft drinks industry. For instance, cola wars have continued for decades between Coca-Cola and PepsiCo, with each aiming to be the exclusive beverage provider to fast food restaurants 19 Through exclusive-offer competition, some customers shift from one manufacturer to the other. For example, Arby's Restaurant Group Inc. decided to switch from PepsiCo to Coca-Cola starting from early 2018 after more than a decade-long contract with PepsiCo 20 Subway had had a partnership with PepsiCo as its primary beverage provider since 1988; however, in 2003, it decided to make a transition to Coca-Cola in its worldwide restaurants 21 From 2015, PepsiCo Canada started to serve Subway Canada as its exclusive beverage and snack provider.22

Another example of the exclusive-offer competition between these two giant suppliers can be observed on university campuses, as noted in Introduction 23 The cola wars forming on university campuses are widespread in the United States and contain some of the key features in our analysis. First, exclusive-offer competition involves a large monetary transfer in return for a long-term monopoly position; for example, in 1998, The University of Maryland at Col-

\footnotetext{
${ }^{19}$ Cola wars have also been observed in the relationship between the cola providers and cinemas. See "CocaCola Lures Regal Cinemas From Rival Pepsi in Latest Steal” The Wall Street Journal, April 9, 2002 (link).

${ }^{20}$ See "Coca-Cola Wins Arby's Away From PepsiCo in Latest Showdown" Bloomberg, August 18, 2017 (link).

${ }^{21}$ See "Coke Wins a 10-Year Contract From Subway, Ousting PepsiCo" The Wall Street Journal, November 28, 2003 (link).

${ }^{22}$ See the second paragraph from the bottom in "Coca-Cola Wins Arby's Away From PepsiCo in Latest Showdown"

${ }^{23}$ Regarding universities' switch between Coca-Cola and PepsiCo, see "Coke vs. Pepsi: University Chooses Side In Cola Wars” Montclair Patch, July 12, 2016 (link).
} 
lege Park signed a 15-year exclusive contract with PepsiCo worth \$57.5 million 24 Second, universities receive not only an annual royalty fee but also a commission fee from the retail sale of some products. The commission rates, which could be correlated to $\beta$ in our analysis, vary across universities. In the case of Ohio State University and Rutgers University, they range from about 20 percent to over 50 percent of the retail sale of drinks and snacks 25 Finally, universities are usually local monopolists; hence, exclusive-offer competition is more likely to play an essential role in exclusion. Although the objective of universities may not be to maximize their profits, our results remain valid even when universities are consumersurplus maximizers 26 Therefore, we think that our analysis fits the cola wars on university campuses well.

Although the above examples are not antitrust cases, the cola wars sometimes lead to antitrust cases. For example, in 1998, PepsiCo filed an antitrust lawsuit against Coca-Cola, alleging that Coca-Cola did not allow food-service distributers who already distribute Coke to distribute Pepsi27 The notable point here is that Coca-Cola was stronger in the foodservice distribution sector of the soft drinks market than in the overall market; the foodservice distributors' share of Coca-Cola was 65 percent and that of PepsiCo was 22 percent, while in the overall soft drinks market Coca-Cola had a 43.9 percent share and PepsiCo had a 30.9 percent share. Therefore, if one side has an extremely higher market share in one area because of exclusive dealing, it will be more likely to take the cola wars to court.

\footnotetext{
${ }^{24}$ See "Thirsting For Cash, Colleges Take Sides In Corporate Cola Wars" The Washington Post, December 23, 1997 (link).

${ }^{25}$ For the case of Ohio State University, see "Refreshing or restricting? Ohio States $\$ 32 \mathrm{M}$ deal with CocaCola brings up questions of transparency" The Lantern, December 19, 2013 (link). In addition, for the case of Rutgers University, see "As of May 2005, Rutgers University no longer has a contract with Coca-Cola" Rutgers University, May, 2005 (link).

26 The results are available upon request.

${ }^{27}$ See “Taking The 'Cola Wars' Into Court” The Washington Post, May 31, 1998 (link).
} 


\section{Conclusion}

This study has explored the existence of anticompetitive exclusive dealing when all upstream firms can make exclusive offers. Most previous studies consider anticompetitive exclusive dealing to deter a potential entrant, which cannot make an exclusive offer. However, in the real-world situation, existing firms are often excluded. Therefore, we need to consider how the existence of exclusive-offer competition affects the possibility of exclusion to apply the model to these cases.

We show that a seemingly small difference in the setting turns out to be crucial. In contrast to the case where one of the upstream firms is a potential entrant, the existence of exclusiveoffer competition eliminates upstream firms' opportunity to earn positive profits when they fail to exclude the rival upstream firm. We point out that this induces upstream firms to make higher exclusive offers and show that when the downstream firm has weak bargaining power, anticompetitive exclusive dealing can be an equilibrium outcome in the two-part tariff setting of the general demand function and Nash bargaining. Moreover, this result holds in various settings and thus the exclusion outcome identified in this study can be widely applied to diverse real-world vertical relationships.

The finding here provides new implications for antitrust agencies; anticompetitive exclusive dealing is more likely to be observed when upstream firms are existing firms. In addition, because the downstream firm has a strong incentive to engage in anticompetitive exclusive dealing, it is more likely to lead the negotiation of anticompetitive exclusive dealing when upstream firms are existing firms.

Despite these contributions, there remain several outstanding issues requiring future research. First, there is a concern about upstream firms' behavior to achieve a market environment where an exclusion equilibrium does not exist. Although we assume that the level of product substitution or bargaining power is exogenously given, upstream firms could control these parameters. Second, there is a concern about this study's relationship with other studies of anticompetitive exclusive dealing. We predict that if we add exclusive-offer competition 
into previous studies, exclusion becomes less costly. We hope that this study will assist future researchers in addressing these issues. 


\section{A Proofs of the results}

\section{A.1 Proof of Proposition 6}

Before proceeding to the proof, we derive firms' equilibrium profits in the subgame after $D$ 's decision in Stage 1.

We first explore the case in which $U_{i}$ 's exclusive offer is accepted in Stage 1. Under exclusive dealing, the final consumer's demand for $U_{i}$ 's product becomes $Q\left(p_{i}\right)=\left(a-p_{i}\right) / b$. We solve the game by using backward induction. In Stage 3, given $w_{i}$ determined in Stage 2, $D$ optimally chooses the price of $U_{i}$ 's product, namely $p^{*}\left(w_{i}\right) \equiv \arg \max _{p_{i}}\left(p_{i}-w_{i}\right) Q\left(p_{i}\right)=$ $\left(a+w_{i}\right) / 2$. The optimal production level of $U_{i}$ 's product supplied by $D$ given $w_{i}$ becomes $Q^{*}\left(w_{i}\right) \equiv Q\left(p^{*}\left(w_{i}\right)\right)=\left(a-w_{i}\right) / 2 b$. In Stage 2, $U_{i}$ and $D$ negotiate and make a contract for the linear wholesale price $w_{i}^{E i}$. By defining $D^{\prime}$ 's profit given $w_{i}$ as $\Pi^{*}\left(w_{i}\right) \equiv\left(p^{*}\left(w_{i}\right)-w_{i}\right) Q^{*}\left(w_{i}\right)$, the bargaining problem between $D$ and $U_{i}$ is described by the payoff pairs $\left(\Pi^{*}\left(w_{i}\right),\left(w_{i}-c\right) Q^{*}\left(w_{i}\right)\right)$ and the disagreement point $(0,0)$. The solution is given by

$$
w_{i}^{E i}=\arg \max _{w_{i}} \beta \log \Pi^{*}\left(w_{i}\right)+(1-\beta) \log \left[\left(w_{i}-c\right) Q^{*}\left(w_{i}\right)\right] .
$$

The maximization problem leads to

$$
w_{i}^{E i}=\frac{a+c-\beta(a-c)}{2} .
$$

The firms' equilibrium profits, excluding the fixed compensation $x_{i}$, are

$$
\pi_{U i}^{E i}=\frac{\left(1-\beta^{2}\right)(a-c)^{2}}{8 b}, \pi_{U j}^{E i}=0, \quad \pi_{D}^{E i}=\frac{(1+\beta)^{2}(a-c)^{2}}{16 b} .
$$

We next explore the case in which $D$ rejects both exclusive offers in Stage 1. In Stage 3, given the wholesale prices $w_{i}$ and $w_{j}$ determined in Stage 2, D optimally chooses the prices of each manufacturer's product $\left(p^{*}\left(w_{i}, w_{j}\right), p^{*}\left(w_{j}, w_{i}\right)\right)$, where

$$
\left(p^{*}\left(w_{i}, w_{j}\right), p^{*}\left(w_{j}, w_{i}\right)\right) \equiv \arg \max _{p_{i}, p_{j}}\left(p_{i}-w_{i}\right) Q\left(p_{i}, p_{j}\right)+\left(p_{j}-w_{j}\right) Q\left(p_{j}, p_{i}\right)
$$


where $i, j \in\{1,2\}$ and $i \neq j$. The production level of each final product supplied by $D$ given $w_{i}$ and $w_{j}$ is given by

$$
Q^{*}\left(w_{i}, w_{j}\right) \equiv Q\left(p^{*}\left(w_{i}, w_{j}\right), p^{*}\left(w_{j}, w_{i}\right)\right)=\frac{a-w_{i}-\gamma\left(a-w_{j}\right)}{2\left(1-\gamma^{2}\right) b} .
$$

In Stage 2, $U_{1}, U_{2}$, and $D$ make contract(s) for the linear wholesale prices $w_{1}^{R}$ and $w_{2}^{R}$. By defining $D^{\prime}$ 's profit from selling $U_{i}$ 's product given $\left(w_{i}, w_{j}\right)$ as $\Pi^{*}\left(w_{i}, w_{j}\right) \equiv\left(p^{*}\left(w_{i}, w_{j}\right)-\right.$ $\left.w_{i}\right) Q^{*}\left(w_{i}, w_{j}\right)$, the bargaining problem between $D$ and $U_{i}$ is described by the payoff pairs $\left(\Pi^{*}\left(w_{i}^{R}, w_{j}^{R}\right)+\Pi^{*}\left(w_{j}^{R}, w_{i}^{R}\right),\left(w_{i}^{R}-c\right) Q^{*}\left(w_{i}^{R}, w_{j}^{R}\right)\right)$ and the disagreement point $\left(\Pi^{*}\left(w_{j}^{R}\right), 0\right)$, where $\Pi^{*}\left(w_{j}^{R}\right)$ is $D^{\prime}$ 's profit when it sells only $U_{j}$ 's product given the linear wholesale price $w_{j}^{R}$. The solution is given by

$$
w_{i}^{R}=\arg \max _{w_{i}} \beta \log \left[\Pi^{*}\left(w_{i}, w_{j}\right)+\Pi^{*}\left(w_{j}, w_{i}\right)-\Pi^{*}\left(w_{j}\right)\right]+(1-\beta) \log \left[\left(w_{i}-c\right) Q^{*}\left(w_{i}, w_{j}\right)\right] .
$$

The maximization problem leads to

$$
w_{i}^{R}=\frac{a(1-\gamma)+c-\beta(a(1-\gamma)-c)}{2-\gamma(1-\beta)},
$$

for each $i \in\{1,2\}$. The resulting profits of the firms are given as

$$
\pi_{U i}^{R}=\frac{\left(1-\beta^{2}\right)(1-\gamma)(a-c)^{2}}{2 b(1+\gamma)(2-\gamma(1-\beta))^{2}}, \quad \pi_{D}^{R}=\frac{(1+\beta)^{2}(a-c)^{2}}{2 b(1+\gamma)(2-\gamma(1-\beta))^{2}} .
$$

We now consider the existence of an exclusion equilibrium. We show that Condition (6) never holds; in other words, by substituting Equations (17) and (18), we have

$$
\Delta \pi_{U}-\Delta \pi_{D}=-\frac{(a-c)^{2}(1+\beta)(8-(1+\gamma)(2-\gamma(1-\beta))(3-\beta))}{16 b(1+\gamma)(2-\gamma(1-\beta))}<0
$$

for all $(\beta, \gamma) \in(0,1)^{2}$. Let $\eta(\beta, \gamma) \equiv-8+(1+\gamma)(2-\gamma(1-\beta))(3-\beta)$. Note that $\eta(\beta, \gamma)<0$ if and only if Condition (19) holds. By differentiating $\eta(\beta, \gamma)$ with respect to $\beta$ and $\gamma$, we have

$$
\begin{aligned}
& \eta_{\beta}(\beta, \gamma) \gtreqless 0 \Leftrightarrow \beta \lesseqgtr K(\gamma) \equiv \frac{-1+2 \gamma}{\gamma}, \\
& \eta_{\gamma}(\beta, \gamma) \gtreqless 0 \Leftrightarrow \beta \gtreqless L(\gamma) \equiv \frac{-1+2 \gamma}{1+2 \gamma} .
\end{aligned}
$$


Note that for $\gamma \in(1 / 2,1], K^{\prime}(\gamma)>L^{\prime}(\gamma)>0$ and $K(\gamma)>L(\gamma)>0$ and that $K(1 / 2)=$ $L(1 / 2)=0$ and $K(1)=1$ and $L(1)=1 / 3$. Figure 7 summarizes the properties of $\eta_{\beta}(\beta, \gamma)$ and $\eta_{\gamma}(\beta, \gamma)$. There are six regions in $(\beta, \gamma) \in[0,1]^{2}$ such that (i) $\eta_{\beta}(\beta, \gamma)=\eta_{\gamma}(\beta, \gamma)=0$, (ii) $\eta_{\beta}(\beta, \gamma)<0, \eta_{\gamma}(\beta, \gamma)>0$, (iii) $\eta_{\beta}(\beta, \gamma)=0, \eta_{\gamma}(\beta, \gamma)>0$, (iv) $\eta_{\beta}(\beta, \gamma)>0, \eta_{\gamma}(\beta, \gamma)>0$, (v) $\eta_{\beta}(\beta, \gamma)>0, \eta_{\gamma}(\beta, \gamma)=0$, and (vi) $\eta_{\beta}(\beta, \gamma)>0, \eta_{\gamma}(\beta, \gamma)<0$. The arrows in Figure 7 indicate the direction of the increase in $\eta(\beta, \gamma)$ for each region. From Figure 7, for $(\beta, \gamma)=(0,1 / 2)$, $\eta(\beta, \gamma)$ takes the locally maximized value in region (i), where we have $\eta(\beta, \gamma)=-5 / 4<0$. More importantly, Figure 7 shows that $\eta(\beta, \gamma)$ is globally maximized in the domain $(\beta, \gamma) \in$ $[0,1]^{2}$ when $(\beta, \gamma)=(1,1)$, where we have $\eta(1,1)=0$. Therefore, $\eta(\beta, \gamma)<0$ for all $(\beta, \gamma) \in(0,1)^{2}$.

Q.E.D.

\section{A.2 Proof of Proposition 7}

We check whether $\pi_{U_{i}}^{E i} \geq \Delta \pi_{D}$ holds. By substituting Equations (17) and (18), we obtain $\pi_{U i}^{E i}-\Delta \pi_{D} \geq 0$ if and only if $\gamma \leq \tilde{\gamma}$ and $\beta \leq \hat{\beta}(\gamma)<1 / 2$.

Q.E.D.

\section{B Results under linear demand and symmetric costs}

This appendix introduces the analysis of the model in Section $3.1+3.3$ under the linear demand function (16). Under the linear demand function, we have

$$
\Pi_{m}=\frac{(a-c)^{2}}{4 b}, \Pi_{d}=\frac{(a-c)^{2}}{(1+\gamma) b} .
$$

Then, the firms' equilibrium profits under exclusive dealing, excluding the fixed compensation $x_{i}$, are

$$
\pi_{U i}^{E i}=\frac{(1-\beta)(a-c)^{2}}{4 b}, \pi_{U j}^{E i}=0, \pi_{D}^{E i}=\frac{\beta(a-c)^{2}}{4 b} .
$$


The profits of firms under no exclusive dealing are given as

$$
\pi_{U i}^{R}=\frac{(1-\beta)(1-\gamma)(a-c)^{2}}{4 b(1+\gamma)}, \pi_{D}^{R}=\frac{(\beta(1-\gamma)+\gamma)(a-c)^{2}}{2 b(1+\gamma)} .
$$

We now explore the existence of an exclusion equilibrium. For the case in which only $U_{i}$ can make an exclusive offer, we check whether Condition (6) holds. By substituting Equations (21) and (22), we have

$$
\Delta \pi_{U}-\Delta \pi_{D}=-\frac{\beta(1-\gamma)(a-c)^{2}}{4 b(1+\gamma)}<0
$$

for all $\gamma \in[0,1)$ and $\beta \in(0,1)$; as with linear wholesale pricing, exclusion never occurs. This result is consistent with Proposition 1 .

By contrast, for the existence of an exclusion equilibrium when both manufacturers can make exclusive offers, we check whether $\pi_{U_{i}}^{E i} \geq \Delta \pi_{D}$ holds. By substituting Equations (21) and (22), we have

$$
\pi_{U i}^{E i}-\Delta \pi_{D}=\frac{(1-2 \beta)(1-\gamma)(a-c)^{2}}{4 b(1+\gamma)} \geq 0
$$

for $\beta \in(0,1 / 2]$. Therefore, an exclusion equilibrium exists if $\beta \leq 1 / 2$, which is consistent with Proposition 2 ,

\section{Results under linear demand and asymmetric costs}

This appendix introduces the analysis of the model in Section 3.4 under the linear demand function (16). We measure $U_{1}$ 's cost advantage by $\theta$, where $c_{2}=\theta p_{m 1}+(1-\theta) c_{1}$ and $p_{m 1}=\left(a+c_{1}\right) / 2$. $\theta=0$ implies that $U_{1}$ has no cost advantage. As $\theta$ increases, $U_{1}$ becomes efficient. We assume the following relationship:

$$
0<\theta<\min \{2(1-\gamma), 1\}
$$

If Condition (25) holds, the upstream market becomes a duopoly if the exclusive offer is rejected. When $D$ accepts $U_{1}$ 's exclusive offer, the firms' equilibrium profits, excluding the fixed compensation $x_{1}$, are

$$
\pi_{U 1}^{E 1}=\frac{(1-\beta)\left(a-c_{2}\right)^{2}}{(2-\theta)^{2} b}, \pi_{U 2}^{E 1}=0, \pi_{D}^{E 1}=\frac{\beta\left(a-c_{2}\right)^{2}}{(2-\theta)^{2} b} .
$$


Likewise, when $D$ accepts $U_{2}$ 's exclusive offer, the firms' equilibrium profits, excluding the fixed compensation $x_{2}$, are

$$
\pi_{U 2}^{E 2}=\frac{(1-\beta)\left(a-c_{2}\right)^{2}}{4 b}, \pi_{U 1}^{E 2}=0, \pi_{D}^{E 2}=\frac{\beta\left(a-c_{2}\right)^{2}}{4 b} .
$$

By contrast, when $D$ rejects both exclusive offers, the firms' equilibrium profits are

$$
\begin{aligned}
\pi_{D}^{R} & =\frac{\left(\theta^{2}+4(1-\gamma)(2-\theta)-(1-\beta)\left((2(1-\gamma)+\theta \gamma)^{2}+(2(1-\gamma)-\theta)^{2}\right)\right)\left(a-c_{2}\right)^{2}}{4 b\left(1-\gamma^{2}\right)(2-\theta)^{2}} \\
\pi_{U 1}^{R} & =\frac{(1-\beta)(2(1-\gamma)+\theta \gamma)^{2}\left(a-c_{2}\right)^{2}}{4 b\left(1-\gamma^{2}\right)(2-\theta)^{2}}, \quad \pi_{U 2}^{R}=\frac{(1-\beta)(2(1-\gamma)+\theta)^{2}\left(a-c_{2}\right)^{2}}{4 b\left(1-\gamma^{2}\right)(2-\theta)^{2}}
\end{aligned}
$$

We now consider the existence of an exclusion equilibrium when both manufacturers make exclusive offers. By substituting (26), (27), and (28), $\pi_{U i}^{E i}+\pi_{D}^{E i}-\pi_{D}^{R} \geq 0$ if and only if $\beta \leq \beta_{i}(\gamma, \theta)$, where

$$
\beta_{1}(\gamma, \theta) \equiv \frac{(2(1-\gamma)+\theta \gamma)^{2}}{4(1-\gamma)^{2}(2-\theta)+\theta^{2}\left(1+\gamma^{2}\right)}, \quad \beta_{2}(\gamma, \theta) \equiv \frac{(2(1-\gamma)-\theta)^{2}}{4(1-\gamma)^{2}(2-\theta)+\theta^{2}\left(1+\gamma^{2}\right)}
$$

The following lemma summarizes the properties of $\beta_{i}(\gamma, \theta)$.

Proposition C.1. $\beta_{i}(\gamma, \theta)$ has the following properties:

1. $0<\beta_{2}<1 / 2<\beta_{1}<1$.

2. $\partial \beta_{1} / \partial \gamma>0$ and $\partial \beta_{2} / \partial \gamma<0$.

3. $\partial \beta_{1} / \partial \theta>0$ and $\partial \beta_{2} / \partial \theta<0$.

4. As $\gamma \rightarrow(2-\theta) / 2, \beta_{1} \rightarrow 1$ and $\beta_{2} \rightarrow 0$.

5. As $\theta \rightarrow 0, \beta_{1} \rightarrow 1 / 2$ and $\beta_{2} \rightarrow 1 / 2$.

Proof. We examine the first property. Note that $\beta_{2}>0$ is obvious. Then, we have

$$
\beta_{1}-\frac{1}{2}=\frac{1}{2}-\beta_{2}=\frac{(\theta(4-\theta)(1-\gamma))^{2}}{2\left(4(1-\gamma)^{2}(2-\theta)+\theta^{2}\left(1+\gamma^{2}\right)\right)}>0
$$




$$
1-\beta_{1}=\frac{(2(1-\gamma)-\theta)^{2}}{4(1-\gamma)^{2}(2-\theta)+\theta^{2}\left(1+\gamma^{2}\right)}>0 .
$$

Therefore, the first property holds. The second and third properties can be derived by the following results; under Condition (25),

$$
\begin{gathered}
\frac{\partial \beta_{1}}{\partial \gamma}=\frac{2 \theta(4-\theta)(2(1-\gamma)+\theta \gamma)(2(1-\gamma)-\theta)}{4(1-\gamma)^{2}(2-\theta)+\theta^{2}\left(1+\gamma^{2}\right)}>0, \\
\frac{\partial \beta_{2}}{\partial \gamma}=-\frac{2 \theta(4-\theta)(2(1-\gamma)+\theta \gamma)(2(1-\gamma)-\theta)}{4(1-\gamma)^{2}(2-\theta)+\theta^{2}\left(1+\gamma^{2}\right)}<0, \\
\frac{\partial \beta_{1}}{\partial \theta}=\frac{4\left(1-\gamma^{2}\right)(2(1-\gamma)+\theta \gamma)(2(1-\gamma)-\theta)}{4(1-\gamma)^{2}(2-\theta)+\theta^{2}\left(1+\gamma^{2}\right)}>0, \\
\frac{\partial \beta_{2}}{\partial \gamma}=-\frac{4\left(1-\gamma^{2}\right)(2(1-\gamma)+\theta \gamma)(2(1-\gamma)-\theta)}{4(1-\gamma)^{2}(2-\theta)+\theta^{2}\left(1+\gamma^{2}\right)}<0 .
\end{gathered}
$$

The fourth and fifth properties are obtained by substituting $\gamma=(2-\theta) / 2$ and $\theta=0$ into $\beta_{i}(\gamma, \theta)$, which is continuous in $\theta$ and $\gamma$.

\section{Exclusive supply contracts when downstream firms com- pete in quantity}

This appendix introduces another case where exclusive-offer competition plays an essential role in exclusive dealing. The upstream market is composed of an upstream monopolist $U$, whose marginal cost is $c \geq 0$. The downstream market is composed of two downstream firms that produce homogeneous products. Each downstream firm produces one unit of the final product by using one unit of input produced by $U$. For simplicity, we assume that the cost of transformation is zero for each $D_{i}$; given the input price $w$, the per unit production cost of $D_{i}$ is given by $c_{D i}=w_{i}$, where $i \in\{1,2\} . D_{1}$ and $D_{2}$ compete in quantity. Let $Q_{i}$ be the production level of $D_{i}$. We assume that inverse demand for the final product $P(Q)$ is given by a simple linear function:

$$
P(Q)=a-b Q
$$

where $Q \equiv Q_{1}+Q_{2}$ is the output of the final product, $a>c$, and $b>0$. 
The model in this appendix contains three stages. In Stage $1, D_{1}$ and $D_{2}$ make exclusive supply offers to $U$ with fixed compensation $y_{i} \geq 0$, where $i \in\{1,2\}$. $U$ can reject both offers or accept one of the offers. As defined in Section 2, let $\omega \in\{R, E 1, E 2\}$ be $U$ 's decision in Stage 1. If $U$ is indifferent between these two exclusive offers and acceptance is more profitable, it accepts one of the offers with probability $1 / 2$. In Stage $2, U$ offers linear wholesale price $w$ to active downstream firms. The equilibrium wholesale price offered by $U$ is denoted by $w^{\omega}$. In Stage 3, active downstream firms order inputs and determine the production level of the final product $Q_{i} . D_{i}$ 's profit is denoted by $\pi_{D i}^{\omega}$. Likewise, $U$ 's profit is denoted by $\pi_{U}^{\omega}$.

\section{D.1 Equilibrium outcomes after Stage 1}

We first explore the case in which $D_{i}$ 's exclusive supply offer is accepted by $U$ in Stage 1 . In Stage 3, given $w, D_{i}$ optimally chooses the production level $Q_{i}^{E i}(w) \equiv \arg \max _{Q_{i}}\left(P\left(Q_{i}\right)-\right.$ $w) Q_{i}=(a-w) / 2 b$. Then, input demand for $U$ becomes $Q^{E i}(w)=Q_{i}^{E i}(w)=(a-w) / 2 b$. In Stage 2, by anticipating these results, $U$ optimally chooses input price $w^{E i} \equiv \arg \max _{w}(w-$ c) $Q(w)=(a+c) / 2$. The equilibrium production levels become $Q^{E i}=Q_{i}^{E i}=(a-c) / 4 b$ and $Q_{j}^{E i}=0$, where $i, j \in\{1,2\}$ and $i \neq j$. The firms equilibrium profits, excluding the fixed compensation $y_{i}$, are

$$
\pi_{D i}^{E i}=\frac{(a-c)^{2}}{16 b}, \pi_{D j}^{E i}=0, \pi_{D}^{E i}=\frac{(a-c)^{2}}{8} .
$$

We next explore the case in which $U$ rejects the exclusive supply offers in Stage 1. In Stage 3, given $w, D_{i}$ competes in quantity. Standard Cournot competition leads to $Q_{i}^{R}(w)=$ $(a-w) / 3 b$. Then, input demand for $U$ becomes $Q^{R}(w)=2(a-c) / 3 b$. In Stage 2 , by anticipating these results, $U$ optimally chooses input price $w^{R} \equiv \arg \max _{w}(w-c) Q^{R}(w)=$ $(a+c) / 2$. The equilibrium production levels become $Q_{1}^{R}=Q_{2}^{R}=(a-c) / 6 b$. The firms' equilibrium profits are

$$
\pi_{D i}^{R}=\frac{(a-c)^{2}}{36 b}, \pi_{U}^{R}=\frac{(a-c)^{2}}{6 b}
$$




\section{D.2 Benchmark analysis}

As in Section 3.2, we assume that $D_{2}$ is a potential entrant and only $D_{i}$ can make an exclusive offer in Stage 1. For an exclusion equilibrium to exist, the equilibrium transfer $y_{i}^{*}$ must satisfy the following two conditions.

First, the exclusive contract must satisfy individual rationality for $U$ :

$$
y_{i}^{*} \geq \Delta \pi_{U}^{c},
$$

where $\Delta \pi_{U}^{c} \equiv \pi_{U}^{R}-\pi_{U}^{E i}$.

Second, it must satisfy individual rationality for $D_{i}$ :

$$
y_{i}^{*} \leq \Delta \pi_{D}^{c}
$$

where $\Delta \pi_{D}^{c} \equiv \pi_{D i}^{E i}-\pi_{D i}^{R}$.

From the above conditions, it is evident that an exclusion equilibrium exists if and only if inequalities (31) and (32) simultaneously hold. This is equivalent to the following condition:

$$
\Delta \pi_{D}^{c} \geq \Delta \pi_{U}^{c}
$$

We now consider the game in Stage 1. By substituting Equations (29) and (30), we obtain

$$
\Delta \pi_{D}^{c}-\Delta \pi_{U}^{c}=\frac{(a-c)^{2}}{144 b}<0
$$

which implies that Condition (33) never holds. Therefore, the exclusion outcomes cannot be observed.

Proposition D.1. Suppose that downstream firms $D_{1}$ and $D_{2}$ compete in quantity by purchasing inputs from upstream monopolist $U$. If $D_{2}$ is a potential entrant and only $D_{1}$ can make an exclusive offer, $D_{1}$ cannot exclude $D_{2}$ via exclusive contracts.

The result here coincides with that of Appendix B in Kitamura, Matsushima, and Sato (2017b) 28

\footnotetext{
${ }^{28}$ More precisely, both models coincide for $k=1$ in their model.
} 


\section{D.3 When exclusive-offer competition exists}

Assume that both downstream firms make exclusive offers. As in Section 3.3, the upper bound of $D_{i}$ 's exclusive offer $y_{i}^{\max }$ depends on $D_{j}$ 's offer, where

$$
y_{i}^{\max } \equiv \begin{cases}\pi_{D i}^{E i} & \text { if } y_{j} \geq \Delta \pi_{U}^{c} \\ \Delta \pi_{D} & \text { if } y_{j}<\Delta \pi_{U}^{c}\end{cases}
$$

and where $\pi_{D i}^{E i}>\Delta \pi_{D}$.

For $y_{j}<\Delta \pi_{U}^{c}$, we have $y^{\max }=\Delta \pi_{D}^{c}$. With this offer, $U_{i}$ earns $\pi_{D_{i}}^{E i}+y^{\max }<\pi_{U}^{R}$ because inequality (34) holds; hence, the individual rationality constraint for $U$ does not hold. Therefore, as in Section 3.3, the non-exclusion equilibrium always exists. For the existence of an exclusion equilibrium, we check whether $\pi_{D i}^{E i} \geq \Delta \pi_{U}^{c}$ holds. By substituting Equations (29) and (30), we obtain

$$
\pi_{D i}^{E i}-\Delta \pi_{U}^{c}=\frac{(a-c)^{2}}{48 b}>0,
$$

which implies that the exclusion outcomes can be observed.

Proposition D.2. Suppose that downstream firms $D_{1}$ and $D_{2}$ compete in quantity by purchasing inputs from upstream monopolist $U$. When both downstream firms can make exclusive offers, there exist both an exclusion equilibrium and a non-exclusion equilibrium. In the exclusion equilibrium, both $D_{1}$ and $D_{2}$ offer $y_{i}^{*}=\pi_{D_{i}}^{E i}>\Delta \pi_{U}$ and $U$ earns all the industry profits.

\section{References}

Abito, J.M., and Wright, J., 2008. Exclusive Dealing with Imperfect Downstream Competition. International Journal of Industrial Organization 26(1), 227-246.

Aghion, P., and Bolton, P., 1987. Contracts as a Barrier to Entry. American Economic Review 77(3), 388-401.

Argenton, C., 2010. Exclusive Quality. Journal of Industrial Economics 58(3), 690-716. 
Bernheim, B.D., and Whinston, M.D., 1998. Exclusive Dealing. Journal of Political Economy 106(1), 64-103.

Bork, R.H., 1978. The Antitrust Paradox: A Policy at War with Itself. New York: Basic Books.

Calzolari, G., and Denicolò, V., 2013. Competition with Exclusive Contracts and Market-Share Discounts. American Economic Review 103(6), 2384-2411.

Calzolari, G., and Denicolò, V., 2015. Exclusive Contracts and Market Dominance. American Economic Review 105(11), 3321-3351.

Choi, J.P., and Stefanadis, C., 2017. Sequential Innovation, Naked Exclusion, and Upfront Lump-Sum Payments. Economic Theory.

DOI: $10.1007 / \mathrm{s} 00199-017-1042-3$

DeGraba, P., 2013. Naked Exclusion by an Input Supplier: Exclusive Contracting Loyalty Discounts. International Journal of Industrial Organization 31(5), 516-526.

Farrell, J., 2005. Deconstructing Chicago on Exclusive Dealing. Antitrust Bulletin 50, 465480.

Fumagalli, C., and Motta, M., 2006. Exclusive Dealing and Entry, when Buyers Compete. American Economic Review 96(3), 785-795.

Fumagalli, C., Motta, M., and Calcagno, C., 2018. Exclusionary Practices: The Economics of Monopolisation and Abuse of Dominance. Cambridge: Cambridge University Press.

Fumagalli, C., Motta, M., and Persson, L., 2009. On the Anticompetitive Effect of Exclusive Dealing when Entry by Merger Is Possible. Journal of Industrial Economics 57(4), $785-811$.

Fumagalli, C., Motta, M., and Rønde, T., 2012. Exclusive Dealing: Investment Promotion may Facilitate Inefficient Foreclosure. Journal of Industrial Economics 60(4), 599-608. 
Gans, J.S., 2013. Intel and Blocking Practices. The Antitrust Revolution: Economics, Competition, and Policy. 6th Edition, edited by J. Kwoka and L. White, New York: Oxford University Press.

Gratz, L., and Reisinger, M., 2013. On the Competition Enhancing Effects of Exclusive Dealing Contracts. International Journal of Industrial Organization 31(5), 429-437.

Kitamura, H., 2010. Exclusionary Vertical Contracts with Multiple Entrants. International Journal of Industrial Organization 28(3), 213-219.

Kitamura, H., Matsushima, N., and Sato, M., 2017a. Exclusive Contracts and Bargaining Power. Economics Letters 151, 1-3.

Kitamura, H., Matsushima, N., and Sato, M., 2017b. How Does Downstream Firms’ Efficiency Affect Exclusive Supply Agreements? mimeo.

http://ssrn.com/abstract=2306922

Kitamura, H., Matsushima, N., and Sato, M., 2018. Exclusive Contracts with Complementary Input. International Journal of Industrial Organization 56, 145-167.

Motta, M., 2004. Competition Policy. Theory and Practice. Cambridge: Cambridge University Press.

Posner, R.A., 1976. Antitrust Law: An Economic Perspective. Chicago: University of Chicago Press.

Rasmusen, E.B., Ramseyer, J.M., and Wiley Jr., J.S., 1991. Naked Exclusion. American Economic Review 81(5), 1137-1145.

Segal, I.R., and Whinston, M.D., 2000. Naked Exclusion: Comment. American Economic Review 90(1), 296-309.

Shen, B., 2014. Naked Exclusion by a Manufacturer without a First-Mover Advantage, mimeo. 
Simpson, J., and Wickelgren, A.L., 2007. Naked Exclusion, Efficient Breach, and Downstream Competition. American Economic Review 97(4), 1305-1320.

Whinston, M.D., 2006. Lectures on Antitrust Economics. Cambridge: MIT Press.

Wright, J., 2008. Naked Exclusion and the Anticompetitive Accommodation of Entry. Economics Letters 98(1), 107-112.

Wright, J., 2009. Exclusive Dealing and Entry, when Buyers Compete: Comment. American Economic Review 99(3), 1070-1081.

Yong, J.S., 1996. Excluding Capacity-Constrained Entrants Through Exclusive Dealing: Theory and an Application to Ocean Shipping. Journal of Industrial Economics 44(2), 115-129.

Yong, J.S., 1999. Exclusionary Vertical Contracts and Product Market Competition. Journal of Business 72(3), 385-406. 


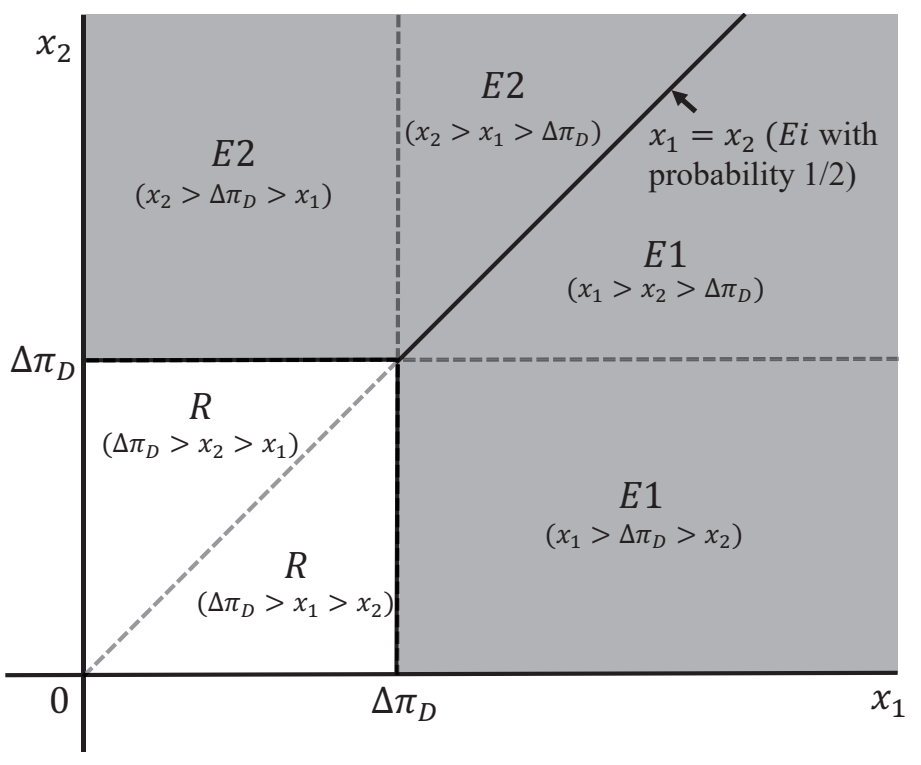

Figure 1: Individual Rationality for $D$ 


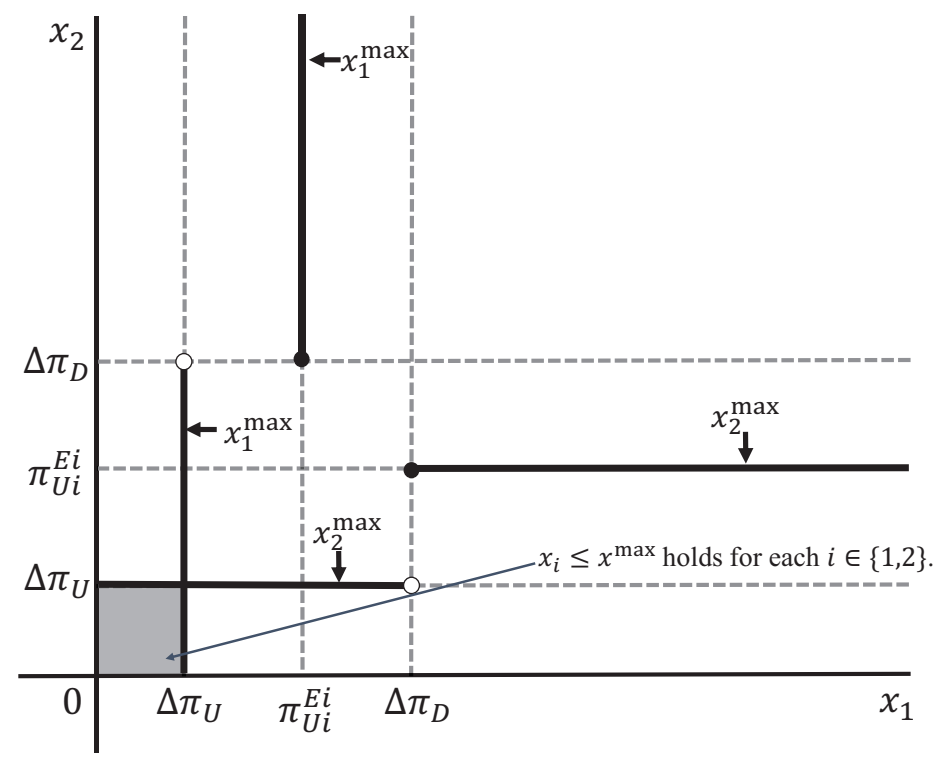

Figure 2: Area of Feasible Offers for $U_{i}\left(\pi_{U i}^{E i}<\Delta \pi_{D}\right)$

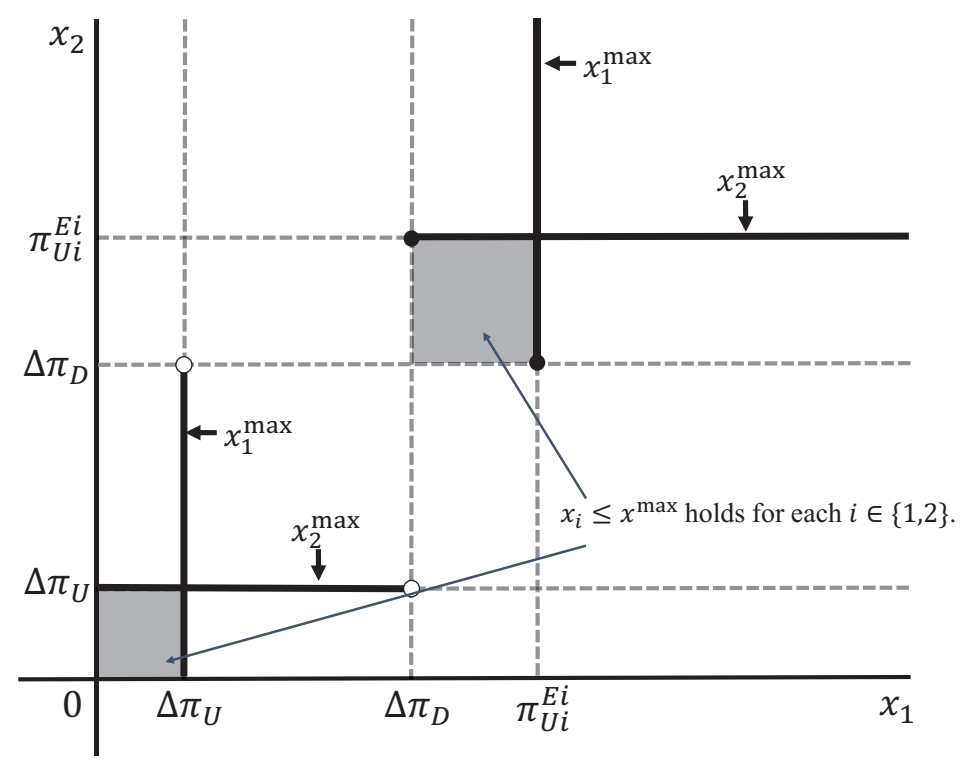

Figure 3: Area of Feasible Offers for $U_{i}\left(\pi_{U i}^{E i} \geq \Delta \pi_{D}\right)$ 


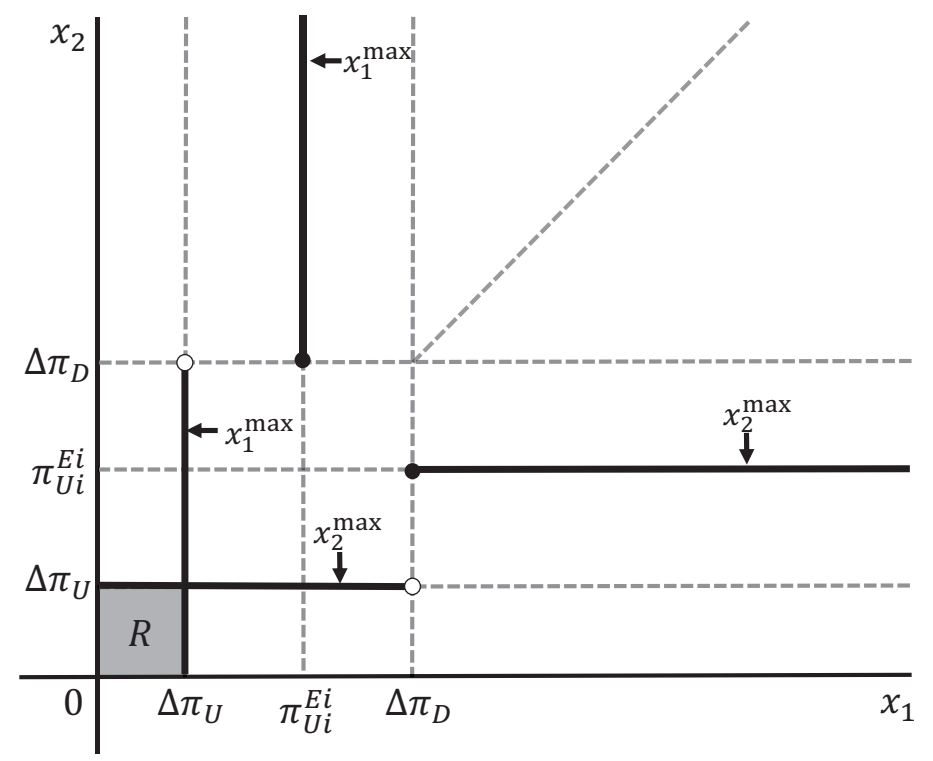

Figure 4: Existence of an Exclusion Equilibrium for $\pi_{U i}^{E i}<\Delta \pi_{D}$

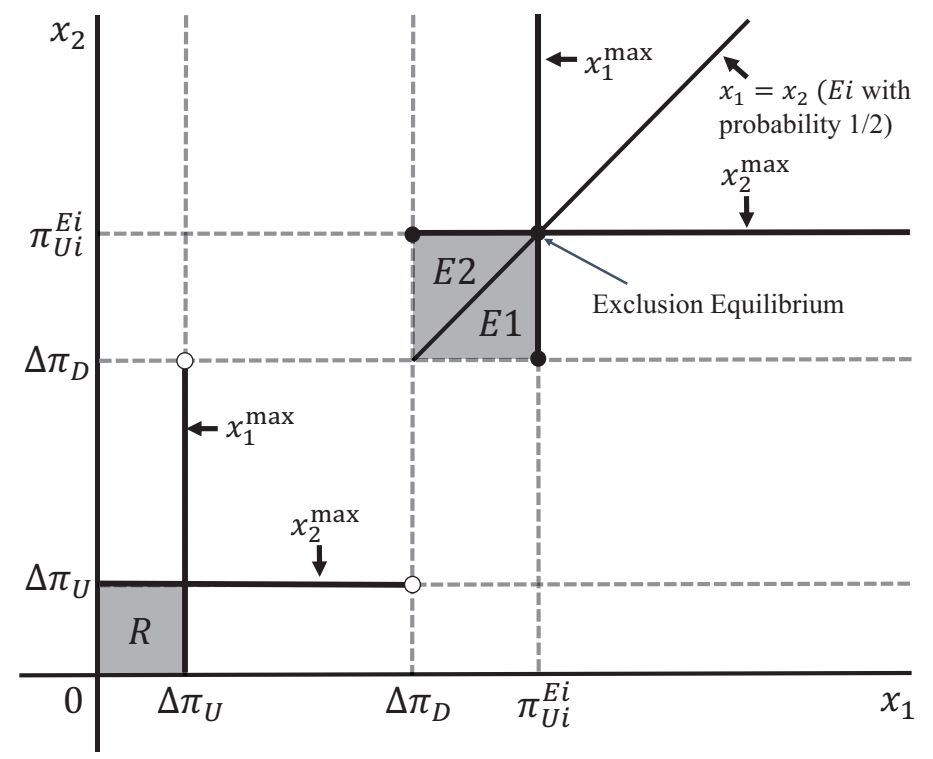

Figure 5: Existence of an Exclusion Equilibrium for $\pi_{U i}^{E i} \geq \Delta \pi_{D}$ 


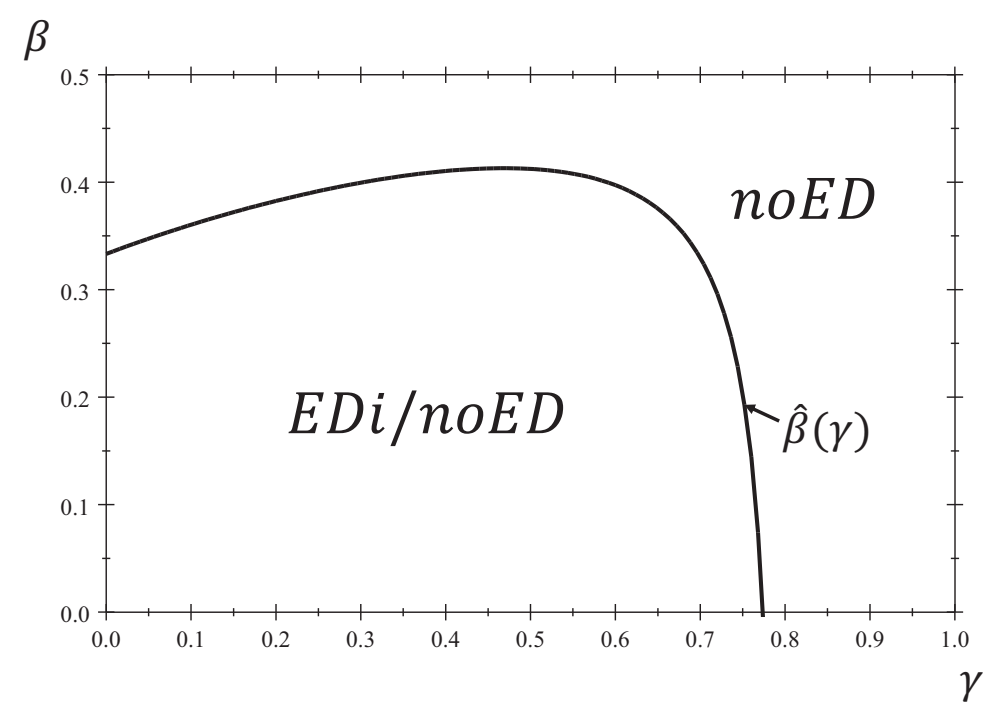

Figure 6: Existence of an Exclusion Equilibrium under Linear wholesale pricing

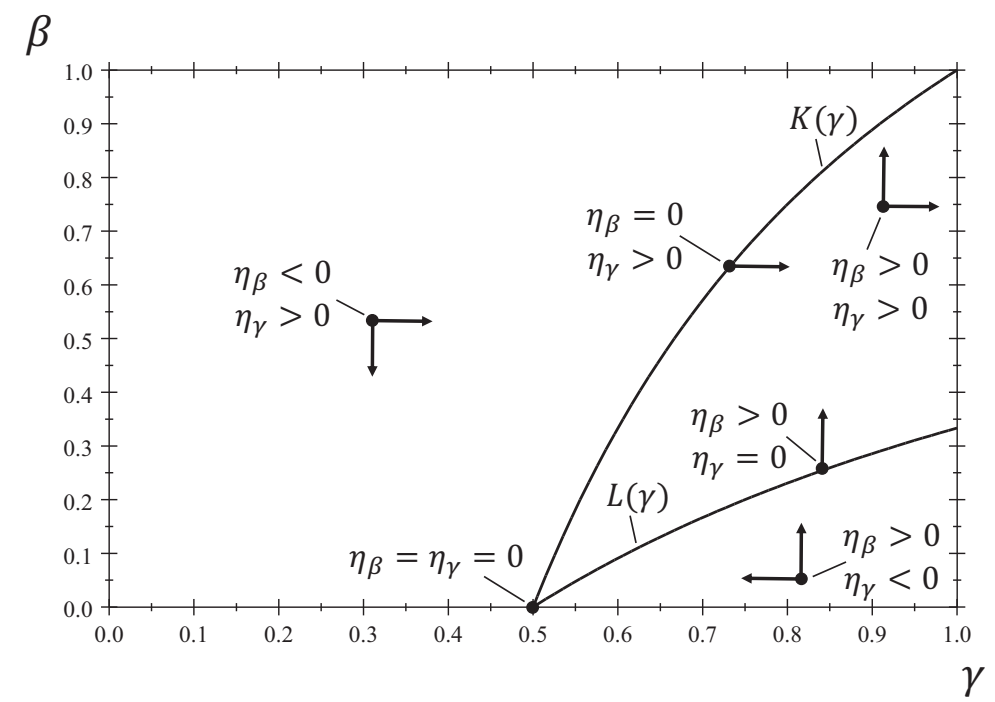

Figure 7: Properties of $\eta_{\beta}(\beta, \gamma)$ and $\eta_{\gamma}(\beta, \gamma)$ 